\title{
FORMAS DEL PROCEDIMIENTO Y GARANTÍAS FUNDAMENTALES DEL PROCESO CIVIL*
}

Manuel Ortells Ramos*

\section{El PUnTO DE PARTIDA DE LA REFLEXIÓN}

Los organizadores de este encuentro académico nos han invitado a realizar aportaciones acerca del tema de "Oralidad y proceso", porque, según han apuntado, "el Tribunal Supremo de Justicia está elaborando un Proyecto de Reforma del Código de Procedimiento Civil basado en la oralidad". Este proyecto respondería a una orientación sintéticamente enunciada con un lema: "Del garantismo formal a la tutela judicial efectiva".

No voy a rehuir el enfoque más específico que ha quedado enunciado en primer lugar. Trataré del mismo principalmente en atención a la experiencia adquirida en la aplicación del modelo procedimental de la Ley de Enjuiciamiento Civil (LEC) española de 2000.

No obstante, desde que leí el lema bajo el que se ampara la reforma recién mencionada, me pareció necesario extender la reflexión a una cuestión previa. El lema enfrenta, de manera implícita, pero poco disimulada, garantías y efectividad, y lo hace de un modo que no deja bien paradas a las primeras. Creo que esto justifica que me ocupe -aunque sólo pueda hacerlo por aproximación-de la interrelación de dos componentes de la ordenación jurídica y de la práctica de la tutela judicial de los derechos: las garantías con las que deben contar quienes, por haberla pedido o por haberse pedido frente a ellos, serán afectados por la resolución sobre la tutela y la forma de la actividad que ha de desarrollarse para Ilegar a esa resolución. En definitiva, la oralidad del procedimiento mediante el

\footnotetext{
* Ponencia presentada por el autor en el III Encuentro Latinoamericano de Postgrados en Derecho Procesal, celebrado en la Universidad Central de Venezuela, del 15 al 17 de octubre de 2009. Trabajo realizado en el contexto del proyecto de investigación DER2008-03240, financiado por el Ministerio de Ciencia e Innovación del Gobierno de España. Investigador principal: Prof. Dr. José Martín Pastor. Colaboración recibida el 29 de marzo y aprobada el 14 de abril de 2010.

** Doctor en Derecho; Catedrático de Derecho Procesal en la Universidad de Valencia (España); Miembro del Instituto Iberoamericano de Derecho Procesal, del Instituto Iberoamericano de Derecho Concursal, de la Societé de Législation Comparée y de la International Association of Procedural Law, de cuyo consejo consultivo forma parte desde 2007. Correo electrónico: manuel.ortells@uv.es.
} 
que se trata la tutela judicial de las situaciones jurídicas de Derecho privado es, precisamente, uno de los modos de articular aquella interrelación que-debemos anticiparlo desde ahora- es siempre problemática.

Una segunda consideración introductoria es completamente obvia: entre las garantías procesales y las formas del procedimiento judicial existe (debe entenderse que existe; o -más- debe postularse que exista) una relación de prioridad en la que las segundas -las formas- están al servicio de las primeras -las garantías-. Estas últimas tienen naturaleza de valores jurídicos -en algunos supuestos, son derechos fundamentales-, mientras que las formas tienen una calidad instrumental o medial respecto de la realización de las garantías.

Esta obviedad se complica en seguida. Primero, porque no es razonable pensar que sólo una determinada forma, entre las varias posibles, es idónea para realizar las garantías, de manera que las opciones legislativas sobre las formas quedan abiertas siempre que no haya perjuicio para las garantías. Segundo, porque la positivación de las garantías procesales en textos jurídicos del más elevado rango -constitucional, transnacional, internacional- ha incluido entre las mismas una que empareja indisolublemente garantías procesales y formas del procedimiento; me refiero al derecho a un proceso sin dilaciones indebidas o a la resolución del proceso en un plazo razonable.

La elección de la forma adecuada para realizar las garantías -elección inevitable, como acabo de apuntar al principio del párrafo anterior- impone tomar en consideración no solamente lo que esas garantías requieren, sino también condicionantes de otra naturaleza. Condicionantes, estos segundos, que ponen de manifiesto que los derechos de las personas respecto de la Justicia no son exclusivamente derechos de libertad, sino también derechos a prestaciones del Estado, cuya satisfacción depende del establecimiento de servicios públicos idóneos.

Del respeto a esas dos clases de referentes (garantías procesales y efectividad de los servicios públicos relacionados con la Justicia) resulta el cumplimiento de la garantía que he destacado dos párrafos más arriba: serán debidas las dilaciones, serán razonables los plazos, si las actividades procesales y el tiempo para su realización vienen impuestos por el respeto a las garantías procesales dentro de un servicio público de Justicia cuyo diseño, dotación y funcionamiento sean correctos.

Estas consideraciones justifican el índice de temas que me propongo tratar en la ponencia.

\section{Panorama normativo de las garantías fundamentales DE LAS PERSONAS EN EL PROCESO CIVIL}

El método de los principios del proceso, de las Prozessmaximen, cuenta con una larga tradición para explicar los criterios generales de ordenación del instrumento mediante el cual se pretende la tutela jurisdiccional y se resuelve sobre la 
misma. Este método fue sometido a crítica, precisamente en el contexto de cultura jurídica en el que se formuló, y una de las prevenciones frente al mismo ha sido la de la carencia de valor normativo de los principios, aunque, como hace tiempo hizo notar R. Phole, algunos de los mismos sí que tienen ese valor. ${ }^{1}$

Las garantías fundamentales del proceso, y la teoría sobre las mismas, tienen una entidad diferente al método de los principios y también un origen histórico más reciente, en especial por lo que se refiere a las garantías fundamentales en el proceso civil.

A las Constituciones -compendio de las opciones políticas básicas sobre la estructura del Estado y la posición de los ciudadanos- se han incorporado determinadas instituciones procesales y algunos principios fundamentales del proceso, pretendiendo reforzar las garantías que el proceso y algunas instituciones del Derecho procesal suponen para las personas.

Junto con lo relativo a la configuración de la jurisdicción -contenido fácilmente explicable en una Constitución, en cuanto es un tema propio de la estructura estatal-, la constitucionalización de los principios básicos del proceso ha tenido mayor tradición en lo que se refiere al proceso penal, dado que en el mismo son más inmediatamente patentes los elementos políticos e ideológicos y también por el especial valor de los derechos de la persona que pueden ser afectados por ese proceso, reconocidos y protegidos ellos mismos por la norma constitucional.

Con posterioridad, la constitucionalización se ha extendido a las garantías procesales en general, más allá de las que sólo rigen en el proceso penal. Además, las garantías procesales fundamentales han alcanzado una nueva formulación normativa mediante su incorporación a textos internacionales y supranacionales sobre derechos humanos.

Este complejo material normativo, dotado de una eficacia (y de una efectividad) jurídica muy diferenciada y de difícil concreción, ha constituido el objeto de una corriente teórica que adquirió consistencia en el último tercio del siglo XX y que conserva plena actualidad. ${ }^{2}$

\footnotetext{
${ }^{1}$ En general, sobre esta materia, puede verse, Ortells Ramos, M., Introducción al Derecho Procesal, Editorial Comares, Granada, 1999, pp. 147-148, y las consideraciones, allí recordadas, de PHole, R., en Stein-Jonas, Kommentar zur Zivilprozessordnung, I, Tübingen, 1972, p. 646; HenCKel, W., Prozessrecht und materielles Recht, Göttingen, 1970, p. 118; HAGEN, J. J., Elemente einer allgemeinen Prozesslehre, Freiburg i. Br., 1972, pp. 84-92; BRüGGEMANN, D., Judex statutor und ludex investigator, Bielefeld, 1968, pp. 101-102.

${ }^{2}$ Debe citarse como texto muy significativo, tanto por el análisis de las garantías y de su protección que se desarrolla en el mismo, como por la información sobre los antecedentes de esta orientación metodológica, la obra Capppellettı, M.; TAllon, D., (Dir.), Fundamental Guarantees of the Parties in Civil Litigation, Milano, Giuffré Editore, New York, Oceana Publications Inc., 1973. Más específicos, por razones diversas, pero igualmente interesantes para comprender esta metodología a través de su aplicación, Cappelletti, M.; Garth, B., El acceso a la justicia, traducción Amaral, S., Colegio de Abogados de La Plata, Buenos Aires, 1983; Trocker, N., Processo civile e Costituzione. Problemi di Diritto tedesco e italiano, Giuffré Editore, Milano, 1974.
} 
Antes de analizar las relaciones entre las garantías fundamentales en el proceso civil y las formas del procedimiento, conviene hacer presente el panorama normativo actualmente existente y que constituye el principal condicionante de aquel análisis. Me referiré brevemente a los textos compartidos, a los propios de la cultura jurídica que me es más próxima y a los que rigen específicamente en Venezuela.

\section{La Declaración Universal de Derechos Humanos y el Pacto Internacional de Derechos Civiles y Políticos}

El artículo 8 la Declaración Universal de Derechos Humanos (DUDH) se refiere, en primer lugar, a la declaración de las garantías procesales no limitadas al proceso penal, con una fórmula, en principio, restrictiva:

"Toda persona tiene derecho a un recurso efectivo ante los tribunales nacionales competentes, que la ampare contra actos que violen sus derechos fundamentales reconocidos por la constitución o por la ley".

No obstante, el art. 10 de la Declaración ya utiliza una fórmula amplia que, como veremos, ha hecho fortuna en otros textos internacionales:

"Toda persona tiene derecho, en condiciones de plena igualdad, a ser oída públicamente y con justicia por un tribunal independiente e imparcial, para la determinación de sus derechos y obligaciones (...)".

En el Pacto Internacional de Derechos Civiles y Políticos (PIDCP), adoptado por la resolución de la Asamblea General 2200 A (XXI), de 16 de diciembre de 1966, junto a normas de ámbito más limitado -como la del art. 2, que establece el derecho a un recurso efectivo en casos de violación de los derechos reconocidos en el Pacto-, el art. 14, apartado 1 contiene la formulación más general de las garantías en el proceso no penal:

"Todas las personas son iguales ante los tribunales y cortes de justicia. Toda persona tendrá derecho a ser oída públicamente y con las debidas garantías por un tribunal competente, independiente e imparcial, establecido por la ley, (...) para la determinación de sus derechos u obligaciones de carácter civil. La prensa y el público podrán ser excluidos de la totalidad o parte de los juicios por consideraciones de moral, orden público o seguridad nacional en una sociedad democrática, o cuando lo exija el interés de la vida privada de las partes o, en la medida estrictamente necesaria en opinión del tribunal, cuando por circunstancias especiales del asunto la publicidad pudiera perjudicar a los intereses de la justicia; pero toda sentencia en materia (...) contenciosa será pública, excepto en los casos en que el interés de menores de edad exija lo contrario, o en las acusaciones referentes a pleitos matrimoniales o a la tutela de menores". ${ }^{3}$

${ }^{3}$ Los paréntesis con puntos suspensivos corresponden a expresiones omitidas por su exclusiva referencia al proceso penal. No he suprimido, en cambio, otras expresiones equívocas, aunque seguramente 
2. El Convenio Europeo para la Protección de los Derechos Humanos y las Libertades Fundamentales, el reconocimiento y protección de los derechos fundamentales en el ámbito de la Unión Europea y la Constitución española de 1978

\section{a) El Convenio Europeo de Derechos Humanos}

El establecimiento de las garantías fundamentales en el proceso civil por el art. 6, apartado 1 del Convenio Europeo de Derecho Humanos (CEDH), se expresa de modo similar al art. 14.1 PIDCP:

"Toda persona tiene derecho a que su causa sea oída equitativa, públicamente y dentro de un plazo razonable, por un Tribunal independiente e imparcial, establecido por la Ley, que decidirá los litigios sobre sus derechos u obligaciones de carácter civil (...). La sentencia deberá ser pronunciada públicamente, pero el acceso a la Sala de Audiencia puede ser prohibido a la prensa y al público durante la totalidad o parte del proceso en interés de la moralidad, del orden público o de la seguridad nacional en una sociedad democrática, cuando los intereses de los menores o la protección de la vida privada de las partes en el proceso así lo exijan o en la medida considerada necesaria por el Tribunal, cuando en circunstancias especiales la publicidad pudiera ser perjudicial para los intereses de la justicia". ${ }^{4}$

Además, el sistema de protección de los derechos humanos en el ámbito del Consejo de Europa, del que es pieza básica el $\mathrm{CEDH}$, cuenta con un órgano de protección jurisdiccional específico de los derechos reconocidos en el Convenio, al que tienen acceso los propios particulares (tras haber agotado las instancias nacionales), ${ }^{5}$ de modo que las fórmulas inevitablemente amplias y genéricas mediante las que se proclaman aquellos derechos, y específicamente en el caso del art. 6.1 CEDH, las garantías procesales en el proceso civil, alcanzan una mayor concreción al ser confrontadas con casos litigiosos en los que tales garantías habrían sido violadas.

\section{b) Reconocimiento y protección en el ámbito de la Unión Europea}

El reconocimiento y protección de los derechos fundamentales -entre ellos, las garantías fundamentales en el proceso civil- en el ordenamiento jurídico

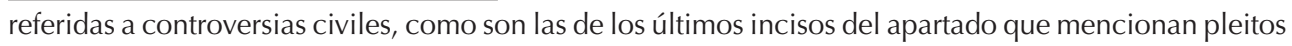
matrimoniales y tutela de menores.

${ }^{4}$ Los paréntesis con puntos suspensivos corresponde a expresiones suprimidas por su exclusiva referencia al proceso penal.

${ }^{5}$ Acerca del sistema de protección jurisdiccional, después de la entrada en vigor del Protocolo número 11, el 1 de noviembre de 1998, puede verse Ortells Ramos, M., "El juez español ante el Convenio Europeo de Derechos Humanos y ante las sentencias del TEDH", en Seminario sobre la jurisprudencia del Tribunal Europeo de Derechos Humanos, Generalitat Valenciana, Valencia, 1998, pp. 13-45. 
de las instituciones que han Ilegado a ser la Unión Europea -por tanto, en un ordenamiento distinto al de cada uno de los países miembros- no ha recorrido un camino fácil y claro, e, incluso, en este momento, no ha llegado a culminar la trascendente etapa que actualmente está recorriendo. ${ }^{6}$

Los textos normativos básicos de las instituciones que han evolucionado hasta la creación de la Unión Europea no incluyeron, hasta tiempos relativamente recientes, ninguna norma que proclamara derechos fundamentales en su ordenamiento jurídico. En ese largo período, fue el Tribunal de Justicia de la Comunidad Europea el que, por vía jurisprudencial y con ocasión del ejercicio de sus competencias en los asuntos litigiosos, reconoció la existencia de unos derechos fundamentales, con fundamento, de una parte, en las tradiciones constitucionales coincidentes de los Estados miembros, y, de otra, en los tratados internacionales sobre derechos humanos, ratificados por esos Estados, y, en especial, en el CEDH.

Esta construcción jurisprudencial alcanzó respaldo normativo con el art. 6 del Tratado Constitutivo de la Unión Europea, hecho en Maastricht el 7 de febrero de 1992, cuyo apartado 2 establece:

"La Unión respetará los derechos fundamentales tal y como se garantizan en el Convenio Europeo para la Protección de los Derechos Humanos y de las Libertades Fundamentales firmado en Roma el 4 de noviembre de 1950, y tal y como resultan de las tradiciones constitucionales comunes a los Estados miembros como principios generales del Derecho Comunitario".

Pero esta norma evidentemente no contenía una proclamación específica de tales derechos. Esta situación quedará superada cuando entre en vigor el Tratado de Lisboa, ${ }^{7}$ cuyo artículo 1.8 remite a la Carta de los Derechos Fundamentales publicada en el "Diario Oficial de la Unión Europea" de 14 de diciembre de 2007 (CDUE). Por lo que interesa a nuestras reflexiones, el art. 47 de esta Carta es el que formula los derechos fundamentales en el proceso no penal. Bajo el epígrafe "Derecho a la tutela judicial efectiva y a un juez imparcial", establece que:

${ }^{6}$ Para una información básica, tanto del desarrollo histórico conducente a la incorporación de los derechos fundamentales al ordenamiento de la Unión Europea, como del contenido de las garantías procesales en ese ámbito, es conveniente ver, entre una bibliografía muy amplia, BıAVATI, P., Europa e processo civile. Metodi e prospettive, G. Giappichelli Editore, Torino, 2003; Martín Dız, F., "Garantías procesales básicas en Carta de Derechos Fundamentales de la Unión Europea", en Herrero de la FuENTE, Alberto A. (editor), La Carta de Derechos Fundamentales de la Unión Europea. Una perspectiva pluridisciplinar, Fundación Rei Alfonso Henríquez, Zamora, 2003, pp. 211-245; MARTín Diz, F. (coord.), Constitución Europea: Aspectos históricos, administrativos y procesales, Tórculo Edicións, Santiago de Compostela, 2006; De la Oliva Santos, A. (director), La Justicia y la Carta de Derechos Fundamentales de la Unión Europea, Colex, Madrid, 2008.

${ }^{7}$ Tratado por el que se modifican el Tratado de la Unión Europea y el Tratado Constitutivo de la Comunidad Europea, firmado en Lisboa el 13 de diciembre de 2007, cuya vigencia depende de la finalización del proceso de ratificaciones. 
"Toda persona cuyos derechos y libertades garantizados por el Derecho de la Unión hayan sido violados tiene derecho a la tutela judicial efectiva respetando las condiciones establecidas en el presente artículo.

Toda persona tiene derecho a que su causa sea oída equitativa y públicamente y dentro de un plazo razonable por un juez independiente e imparcial, establecido previamente por la ley. Toda persona podrá hacerse aconsejar, defender y representar.

Se prestará asistencia jurídica gratuita a quienes no dispongan de recursos suficientes siempre y cuando dicha asistencia sea necesaria para garantizar la efectividad del acceso a la justicia".

C) Reconocimiento y protección en la Constitución española de 1978

El precepto básico para el reconocimiento de las garantías fundamentales en procesos no penales, en la Constitución española (CE), es el art. 24, que, aunque en buena parte de su literalidad demuestra su principal preocupación por el proceso penal, reconoce derechos fuera de ese proceso:

"1. Todas las personas tienen derecho a obtener la tutela judicial efectiva de los jueces y magistrados en el ejercicio de sus derechos e intereses legítimos, sin que, en ningún caso, se pueda producir indefensión.

2. Asimismo, todos tienen derecho al Juez ordinario predeterminado por la ley, a la defensa y a la asistencia de letrado, (...) a un proceso público sin dilaciones indebidas y con todas las garantías, a utilizar los medios de prueba pertinentes para su defensa (...)".

El art. 120 CE establece normas constitucionales que vinculan la regulación del procedimiento judicial por el legislador ordinario:

"1. Las actuaciones judiciales serán públicas, con las excepciones que prevean las leyes de procedimiento.

2. El procedimiento será predominantemente oral (...).

3. Las sentencias serán siempre motivadas y se pronunciarán en audiencia pública".

Los derechos procesales correspondientes se tienen, como los demás derechos, en condiciones de igualdad (art. 14 CE). Y, para favorecer que esa igualdad sea real y efectiva en el ejercicio de los derechos procesales de las partes, el art. 119 CE establece que:

"La justicia será gratuita cuando así lo disponga la ley y, en todo caso, respecto de quienes acrediten insuficiencia de recursos para litigar".

La protección de los derechos fundamentales se lleva a cabo, además de por la acción de los tribunales ordinarios, mediante un recurso de amparo ante 
el Tribunal Constitucional (art. 53. 2 y 3, art. 160.1, b), art. 162.1, b LEC) y la especial fuerza jurídica de las normas constitucionales, aunque no reconozcan derechos fundamentales, mediante el control de la constitucionalidad por el Tribunal Constitucional (art. 161.1, a) y art. 163 LEC).

3. La Convención Americana sobre Derechos Humanos (Pacto de San José) y la Constitución de Venezuela

\section{a) Las garantías procesales en el Pacto de San José}

El Pacto de San José (CADH) reconoce las garantías fundamentales en los procesos no penales en el apartado 1 de su artículo 8, según el cual-suprimiendo las referencias a la materia penal:

"Toda persona tiene derecho a ser oída, con las debidas garantías y dentro de un plazo razonable, por un juez o tribunal competente, independiente e imparcial, establecido con anterioridad por la ley, (...) o para la determinación de sus derechos y obligaciones de orden civil, laboral, fiscal o de cualquier otro carácter".

Como es sabido, los arts. 33 y siguientes del Pacto de San José establecen un sistema de protección que se asemeja al que originariamente estableció el $\mathrm{CEDH}$, principalmente en cuanto a que las denuncias y quejas por violación de los derechos reconocidos en el Convenio no puede ser directamente planteada ante la Corte por los particulares, sino sólo por la Comisión, ante la cual sí que han podido presentar sus solicitudes los particulares. También los Estados signatarios pueden presentar denuncias de incumplimiento ante la Comisión, si el Estado signatario contra el que se dirijan ha reconocido esta competencia de la Comisión (art. 45.1 de la Convención). ${ }^{8}$

\section{b) Las garantías procesales en la Constitución de Venezuela}

La Constitución de la República Bolivariana de Venezuela de 1999 (CV) formula de modo muy completo el reconocimiento de las garantías fundamentales en los procesos no penales.

$\left.1^{\circ}\right)$ De acuerdo con su art. 26:

"Toda persona tiene derecho de acceso a los órganos de administración de justicia para hacer valer sus derechos e intereses, incluso los colectivos o difusos, a la tutela efectiva de los mismos y a obtener con prontitud la decisión correspondiente.

${ }^{8}$ De acuerdo con la información resultante del sitio Web de la Corte Interamericana de Derechos Humanos, Venezuela ratificó el Pacto el 23 de junio de 1977 (Instrumento depositado el 9 de agosto de 1977), reconoció la competencia de la Corte el 24 de junio de 1981 y la competencia de la Comisión, para conocer de denuncias de acuerdo con el art. 45.1, el 9 de agosto de 1977. En http://www. corteidh.or.cr [visitado el 15/03/2010]. 
El Estado garantizará una justicia gratuita, accesible, imparcial, idónea, transparente, autónoma, independiente, responsable, equitativa y expedita, sin dilaciones indebidas, sin formalismos o reposiciones inútiles".

$\left.2^{\circ}\right)$ Según el art. $49 \mathrm{CV}$ : "El debido proceso se aplicará a todas las actuaciones judiciales", lo que tiene como consecuencia, específicamente para los procesos no penales, que:

"3. Toda persona tiene derecho a ser oída en cualquier clase de proceso, con las debidas garantías y dentro del plazo razonable determinado legalmente, por un tribunal competente, independiente e imparcial establecido con anterioridad. Quien no hable castellano o no pueda comunicarse de manera verbal, tiene derecho a un intérprete.

4. Toda persona tiene derecho a ser juzgada por sus jueces naturales en las jurisdicciones ordinarias, o especiales, con las garantías establecidas en esta Constitución y en la ley".

Por otra parte, el art. $257 \mathrm{CV}$ establece normas de rango constitucional a las que deberá sujetarse la regulación legal del proceso -con el fin, hay que pensar, de que puedan ser efectivos los derechos fundamentales procesales reconocidos:

"El proceso constituye un instrumento fundamental para la realización de la justicia. Las leyes procesales establecerán la simplificación, uniformidad y eficacia de los trámites y adoptarán un procedimiento breve, oral y público. No se sacrificará la justicia por la omisión de formalidades no esenciales".

$3^{\circ}$ ) Los derechos mencionados se tienen en condiciones de igualdad, no sólo jurídica, sino tendencialmente -porque esto depende de una regulación y de una actividad prestacional pública- real y efectiva (art. $21 \mathrm{CV}$ ).

$4^{\circ}$ ) Por fin, el art. 23 CV integra los textos internacionales sobre derechos humanos en el ordenamiento jurídico interno, con una eficacia jurídica por lo menos tan intensa como el art. 10.2 CE, porque:

"Los tratados, pactos y convenciones relativos a derechos humanos, suscritos y ratificados por Venezuela, tienen jerarquía constitucional y prevalecen en el orden interno, en la medida en que contengan normas sobre su goce y ejercicio más favorables a las establecidas por esta Constitución y la ley de la República, y son de aplicación inmediata y directa por los tribunales y demás órganos del Poder Público".

III. UNA APROXIMACIÓN AL CONTENIDO DE LAS GARANTÍAS FUNDAMENTALES DEL PROCESO CIVIL Y A LAS EXIGENCIAS QUE DERIVAN DE LAS MISMAS RESPECTO DE LAS FORMAS DEL PROCEDIMIENTO

Hemos visto en el anterior apartado cómo los textos fundamentales de ámbito interno e internacional incluyen, en algunos supuestos, normas sobre la forma 
del procedimiento y, casi siempre, derechos respecto de la duración razonable del proceso. Volveremos sobre estos dos aspectos en los apartados IV al V de la ponencia. En este apartado nos proponemos exponer una síntesis sistemática de las garantías procesales que, en el apartado I, hemos sostenido que son prioritarias, así como las principales manifestaciones del ajuste o la adecuación a las mismas de las formas del procedimiento. Para evitar duplicidades -si no de tratamiento, sí de referencia a cada cuestión relevante- expondremos el segundo aspecto con ocasión de tratar de la garantía correspondiente.

\section{Las garantías fundamentales se tienen ante y respecto de un tribunal y del ejercicio de su específica potestad (la potestad jurisdiccional)}

La que podemos denominar garantía jurisdiccional es básica y fundamental respecto de todas las garantías que consideraremos a continuación. Estas garantías las ostentan las personas frente o con respecto a unos órganos específicos del poder público y en cuanto éstos son los que ejercen (los únicos que pueden ejercer) una potestad jurídico-pública también específica: los tribunales de justicia investidos de la potestad jurisdiccional.

Ciertamente, en cada Estado -o en cada organización internacional o transnacional que cuente en su estructura con órganos dotados de potestad jurisdiccional- son diferentes los requisitos de los tribunales de justicia y de los servidores públicos que son titulares de los mismos. Pero un repaso de los textos fundamentales que hemos recogido en el anterior apartado demuestra que todos ellos establecen unos estándares similares: tribunales independientes, imparciales, establecidos por la ley de manera previa al litigio que han de enjuiciar, lo que incluye que sea la ley la que les atribuya competencia para conocer de los asuntos. ${ }^{9}$

Recordemos, no obstante, que la principal cuestión a considerar aquí -dejando aparte una mayor profundización en la esencia de la garantía- es si su efectivo cumplimiento impone o requiere, y en qué medida o sentido, la opción por una forma determinada de la actividad de relación entre jueces y justiciables.

Lo que, en sustancia, esta garantía implica es que un juez -quien responda a las características para ser tenido por tal en un ordenamiento- sea el real

\footnotetext{
${ }^{9}$ Cuando la garantía jurisdiccional la establece la norma suprema de un ordenamiento estatal, es más sencillo determinar cuál es el alcance de la garantía; por ejemplo, para el Derecho español, los casos considerados en OrTelLs, Introducción, cit. nota n. 1, pp. 135-136; PıCó I JunOY, J., Las garantías constitucionales del proceso, J. M. Bosch Editor, Barcelona, 1997, pp. 97-101. Para la incidencia de esta garantía en el ámbito de la Convención Interamericana de Derecho Humanos, véanse, entre otras, Corte Interamericana de Derechos Humanos, Caso 19 Comerciantes Vs. Colombia, Sentencia 5 julio 2004, núms. 164-174; Corte Interamericana de Derechos Humanos, Caso Yatama Vs. Nicaragua, Sentencia 23 junio 2005, núms. 170-175.
} 
destinatario de las diversas aportaciones de parte (y de otros sujetos procesales) que conforman la actividad procesal, sea el director de esa actividad-con una amplitud que puede ser diferente según ordenamientos- $y$, obviamente, quien esté investido de la potestad de dictar sentencia.

Lo que importa para la satisfacción de esta garantía es que sea el juez quien, de verdad, ostente y ejerza esos poderes. Eso se producirá si las normas así lo establecen y son cumplidas, tanto si la forma de la actividad procesal es escrita -el juez tendrá el deber de considerar los "autos", el "expediente"-, como si es oral -en este caso se da la evidencia de la presencia judicial (hay que pensar que atenta) durante el desarrollo de la actividad procesal-.

Si del plano normativo pasamos a considerar su cumplimiento real, cabe constatar que la forma escrita facilita de hecho el distanciamiento del juez respecto del desarrollo del proceso -que tiende a ser controlado por el personal auxiliar del tribunal-, salvo las resoluciones de dirección procesal más importantes y, obviamente, la emisión de la sentencia. ${ }^{10}$ No obstante, esto sería resultado de una posible perversión de la forma (escrita), pero no una inevitable consecuencia de la misma.

\section{La garantía de acceso a los tribunales}

Varios de los textos normativos básicos que hemos reseñando en el apartado II (art. $10 \mathrm{DUDH}$; art. 14.1 PIDCP; art. 8.1 CADH; art. 6.1 CEDH) formulan la declaración de que toda persona tiene derecho a ser oída por el tribunal para la determinación de sus derechos y obligaciones de carácter civil (o de otra naturaleza no penal).

El sentido de esta declaración comprende tanto la posición de la persona que insta la actuación de los tribunales, mediante una pretensión de tutela jurisdiccional relativa a aquella clase de derechos -y mediante otras aportaciones dirigidas a obtener su concesión-, como la posición de la persona frente a la que esa pretensión ha sido formulada y que, por consiguiente, tiene derecho a ser oída, a participar en el proceso con diversas aportaciones, para influir en la determinación de sus obligaciones, que, como resultado del proceso, realizará el tribunal.

\footnotetext{
${ }^{10}$ Ortells, Introducción, cit. nota n. 1, pp. 231-232; Prieto-Castro, L., "Precisiones sobre oralidad y escritura", en Estudios y comentarios para la teoría y la práctica procesal civil I, 1950, p. 88; SERRA Domínguez, M., "Liberalización y socialización del proceso civil (Las facultades del juez en la legislación y en la realidad procesales)", Revista de Derecho Procesal Iberoamericano Nos. 2-3, 1972, p. 526; Almagro Nosete, J., "Garantías constitucionales del proceso civil", Justicia número especial, 1981, p. 21; VÁzquez Sotelo, J. L., "La oralidad y la escritura en el moderno proceso civil español y su influencia sobre la prueba", en CARPI, F., ORTELLS, M., Eds., Oralidad y escritura en un proceso civil eficiente, v. II, Asociación Internacional de Derecho Procesal - Universitat de València, Valencia, 2008, pp. 259-261.
} 
En este apartado no me referiré a este significado más amplio de la que podemos Ilamar garantía de audiencia en justicia -del que trataré en los apartados 3 al 5-, sino una garantía más específica, incluida en la anterior, pero que, en diversos textos normativos básicos, se formula de modo separado: el derecho a interponer una pretensión de tutela ante los tribunales, que dará origen a un proceso, en el que se resolverá sobre ella, con respeto al conjunto de garantías que aquí consideramos. Se trata del derecho a un recurso efectivo, al que se refieren el art. $8 \mathrm{DUDH}$ y el art. $25 \mathrm{CADH}$, aunque limitadamente a la protección de los derechos fundamentales, y, sin esa limitación, del derecho a la tutela judicial efectiva (de los arts. 24 CE y 47 CDUE), o del derecho de acceso a los tribunales para hacer valer los derechos e intereses y a la tutela judicial de los mismos (art. $26 \mathrm{CV}$ ). Este tratamiento separado se justifica también, según veremos, por la mutuas implicaciones entre esta garantía y la forma del acto en el que se formula la pretensión de tutela.

En la breve consideración de la esencia de esta garantía, apuntaré que la misma tiene, o puede tener, relevancia tanto por lo que positivamente impone, como por lo que excluye.

En síntesis, el aspecto excluyente o negativo se relaciona con la justificación del principio dispositivo en sentido estricto: no puede ser otorgada tutela jurisdiccional si no es instancia del (que afirma ser) titular del interés jurídico privado lesionado o amenazado, y dentro de los límites de aquella instancia. De este modo, en el más alto nivel normativo, quedaría garantizada la concepción del Derecho privado que protege la autonomía individual frente a injerencias ajenas. No obstante, este aspecto negativo o excluyente no tiene una eficacia autónoma en esta garantía fundamental. En ocasiones porque directamente lo impide la propia formulación normativa -así, muy destacadamente, el art. $26 \mathrm{CV}$, que relaciona el derecho de acceso con todos los derechos e intereses "incluso los colectivos y difusos"-. En todas las demás formulaciones de la garantía porque la legitimación acaba por ser uno de los presupuestos para que la pretensión de tutela se admita o sea estimada; es decir, es uno de los requisitos importantes para el significado o relevancia positivos de la garantía.

Este aspecto positivo puede sintetizarse así:11

$1^{\circ}$ ) Comprende el derecho a plantear la pretensión ante los tribunales y a que éstos deban pronunciarse sobre ese planteamiento, aunque sea en el sentido de inadmisión.

11 Puede ampliarse la información en Ortells, Introducción, cit. nota n. 1, pp. 137-141; PICÓ, Las garantías, cit. nota n. 9, pp. 45-53; Bonet Navarro, A., "El acceso a la justicia", en Gutiérrez-Alviz Conradi (Dir.), Justicia: poder y servicio público, Consejo General del Poder Judicial, Madrid, 2007, pp. 95-118. 
$2^{\circ}$ ) Además, incluye el derecho a que el tribunal se pronuncie sobre la pretensión misma, estimándola o desestimándola, siempre que hayan sido cumplidos los requisitos de los que las leyes procesales hacen depender la prosecución del proceso, hasta su terminación por sentencia, y la admisión de un pronunciamiento de fondo. Entre estos requisitos es frecuente que los ordenamientos incluyan el de que la actuación procesal para pretender la tutela deba ser dirigida por un profesional del Derecho, por un abogado. También es posible que, sin imponerlo como requisito de admisibilidad, autoricen a la parte a que utilice ese servicio profesional. La amplia incidencia de este requisito en el conjunto de la actividad procesal y las peculiaridades de la solución de algunos de sus problemas, justifican que nos ocupemos del mismo al tratar de la garantía de la igualdad en el sub-apartado 5 de este mismo apartado.

$\left.3^{\circ}\right)$ Siendo cierto el condicionante apuntado en el apartado anterior, la garantía también comprende una exigencia de que tales requisitos procesales no sean de imposible cumplimiento, absurdos o de cualquier otro modo contrarios a las normas fundamentales que establecen la garantía de acceso a los tribunales para obtener tutela judicial. ${ }^{12}$

$4^{\circ}$ ) En fin, la garantía requiere que el pronunciamiento judicial sea motivado, que exponga las razones que justifican el sentido de la decisión. ${ }^{13}$

¿Impone esta garantía una forma determinada para el acto procesal mediante el que se pretende una tutela judicial, dando lugar, con ello, al inicio del proceso?

La función que este acto cumple en el proceso requiere que exista una constancia precisa y permanente de la tutela que ha sido pretendida. Estos resultados se alcanzan más fácilmente con la escritura, pero como la oralidad no excluye la documentación -y ésta, además, puede tener diferentes grados de detalle- no puede decirse que esta forma sea esencialmente incompatible con el acto de petición de tutela judicial.

\footnotetext{
${ }^{12}$ Tratando este tema, con pronunciamientos en diferentes sentidos, pueden verse algunas sentencias recientes del TEDH: (Gran Sala) sentencia de 14 diciembre 2006, Caso Markovic y otros contra Italia; (Sección 4a ) sentencia de 27 abril 2004, Caso Gorraiz Lizárraga y otros contra España; (Gran Sala) sentencia de 27 junio 2000, Caso Frydlender contra Francia; (Sección 3ª) sentencia de 27 febrero 2001, Caso R. contra Bélgica; sentencia de 8 diciembre 1999, Caso Pellegrin contra Francia; sentencia de 21 noviembre 2001, Caso Al-Adsani contra Reino Unido; sentencia de 21 noviembre 2001, Caso Mc Elhinney contra Irlanda; sentencia de 28 octubre 1998, Caso Osman contra Reino Unido.

${ }^{13}$ Sobre la relevancia de la motivación, y para el ámbito americano, véanse, por ejemplo, Corte Interamericana de Derechos Humanos, Caso Yatama Vs. Nicaragua, Sentencia 23 junio 2005, núms. 147-164; Corte Interamericana de Derechos Humanos, Caso Claude Reyes y otros Vs. Chile, Sentencia 19 septiembre 2006, núms. 118-122, 131-139.
} 


\section{La garantía de la contradicción}

La garantía de la contradicción consiste en la efectiva posibilidad de que toda persona que se halle expuesta a ser afectada en su posición jurídica por una resolución judicial, pueda influir en el contenido de la misma, adquiriendo conocimiento de los materiales en que ha de fundarse, tomando postura respecto de los mismos y participando en la introducción en el proceso de esos materiales.

Su formulación normativa en los textos fundamentales se expresa como derecho a ser oído por el tribunal con justicia (art. 10 DUDH), con las debidas garantías (art. 14.1 PIDCP; art. 8.1 CADH; art. $49 \mathrm{CV}$ ), equitativamente (art. 6.1 CEDH; art. 47 CDFUE). En la CE encontramos su formulación en el art. 24: en su párrafo 1, cuando prohíbe situaciones de indefensión; en su párrafo 2, tanto de un modo genérico (derecho a un proceso con todas las garantías), cuanto de un modo específico, al establecer unos componentes parciales del principio no limitados al proceso penal.

\section{a) Las personas titulares de la garantía y el contenido de ésta}

La garantía asiste a los que pueden ser afectados por la cosa juzgada que la sentencia produzca y por su eficacia ejecutiva. ${ }^{14}$ Por descontado que en esa descripción están contenidas las personas que, inicialmente, son partes en el proceso, pero la garantía de contradicción impone también que la ley prevea un régimen adecuado para que los que, en principio, son terceros, pero pueden verse afectados por la sentencia, tengan posibilidad de participar en el proceso. ${ }^{15}$

Por lo demás, la garantía se reconoce a las partes sea cual sea la posición que ocupen en el proceso (actor o demandado; acusador o acusado), sin que el término utilizado en su reconocimiento constitucional (defensa) pueda interpretarse en un sentido de "tutela exclusiva de quien resiste a la acción de otro", sino como "posibilidad de adecuado desarrollo de tesis...- por todas las partes". ${ }^{16}$

En cuanto al contenido de la garantía, se integra, en primer lugar, por una posibilidad efectiva y real de llevar a cabo las actividades que luego veremos. Concuerdan los autores en que el respeto del principio exige sólo conceder

\footnotetext{
${ }^{14}$ Grunsky, W., Grundlagen des Verfahrensrecht, Bielefeld, 1974, pp. 227-232; Trocker, Processo, cit. nota n. 2, pp. 423-448; SCHLOSSER, P., "Urteilswirkung und rechtliches Gehör", en Juristenzeitung, 1967, pp. 431-437; Wolf, M., "Rechtliches Gehör und die Beteiligung Dritter am Rechtstreit", en Juristenzeitung, 1971, pp. 405-409; ORTELLs, Introducción, cit. nota n. 1, pp. 166-167.
}

${ }^{15}$ Sobre la última cuestión mencionada puede verse BONET, "El acceso", cit. n. 11, pp. 77-79

${ }^{16}$ Chiavario, M., Processo e garanzie della persona, Milano, 1977, p. 74. 
una posibilidad y no su efectiva utilización (tal vez porque ello no depende del legislador), pero afirman también que tal posibilidad no debe ser ficticia o formal, ni de dificilísimo aprovechamiento. ${ }^{17}$

Un completo análisis de la efectividad de los procedimientos de notificación y de la suficiencia de plazos y términos para la realización de las actividades procesales es evidente que no puede ser aquí asumido. Baste con señalar que una disciplina tan formal como la que se ocupa de ello puede comprometer la vigencia de la garantía de contradicción y que considerada como un tema en el que se manifiestan las tensiones entre el respeto a esta garantía y la exigencia de un funcionamiento ágil del proceso, viene a adquirir una importancia trascendental. El Tribunal Constitucional (TC) español ha hecho notar, reiteradamente, respecto del acto de comunicación que contiene el llamamiento del demandado al proceso que "el artículo 24.1 de la Constitución contiene un mandato implícito al legislador -y al intérpreteconsistente en promover la defensión, en la medida de lo posible, mediante la correspondiente contradicción. Lo que conduce a establecer el emplazamiento personal a los que puedan comparecer como codemandados, siempre que ello resulte factible". ${ }^{18}$

Esa efectiva posibilidad ha de proyectarse, en primer término, sobre la adquisición de conocimiento de lo que constituye el objeto del proceso y de los materiales fácticos y jurídicos que pueden incidir en la resolución sobre ese objeto. Este conocimiento constituye el necesario presupuesto para una puesta en práctica eficaz de las posibilidades que encierra la contradicción y que luego mencionaremos.

La adquisición de conocimiento ha de referirse tanto a las aportaciones de la contraparte, cuanto a los resultados de una actividad de investigación oficial si la ley establece esta última.

Es coherente con el principio de contradicción que, con carácter previo al ejercicio de ciertos poderes de oficio que la ley procesal confiera al juzgador, éste deba poner a debate la posibilidad de ejercitarlos en el caso concreto. Una manifestación específica de este aspecto del principio es la posibilidad de condicionar la virtualidad del principio iura novit curia a una previa discusión de la tesis jurídica que el órgano jurisdiccional considera correcta, pero que no ha sido planteada por las partes $y$, por tanto, puede pasar desapercibida para éstas.

\footnotetext{
17 Rosemberg, L.; Schwab, K. H., Zivilprozessrecht, München, 1977, p. 430; Phole en Stein-Jonas, Kommentar, cit. nota n. 1 p. 659; Trocker, Processo, cit. nota n. 2, pp. 465-505.

${ }_{18}$ Puede ampliarse la información sobre esto en PIcó, Las garantías, cit. nota n. 9, pp. 53-58; Bonet, "El acceso", cit. n. 11, pp. 54-59. Véase, además, del TEDH (Sección 4ª) sentencia de 15 de octubre de 2002, Caso Cañete de Goñi contra España.
} 
El paso de esa situación de conocimiento al ejercicio de influencia sobre la resolución que vaya a dictarse, implica, como contenido mínimo, la posibilidad de formular alegaciones de hecho y de derecho acompañadas de las correspondientes peticiones. ${ }^{19}$ Las alegaciones pueden referirse -han de poder referirse- tanto a la admisibilidad del pronunciamiento sobre el fondo, como al sentido (estimatorio o desestimatorio) de ese pronunciamiento.

Una mayor intensidad en la influencia sobre la resolución la supone la posibilidad de probar las alegaciones formuladas y de intervenir en la práctica de pruebas propias, de la contraparte y de las acordadas de oficio por el juez. Este aspecto de la garantía de la contradicción ${ }^{20}$ plantea diversos problemas, por lo que conviene darle un tratamiento separado.

En fin, como sería contrario a la esencia del proceso que éste se convirtiera en una actividad interminable, no es contrario al contenido esencial de la garantía de contradicción que la ley discipline el ejercicio de las posibilidades que comporta, sometiéndolas a un régimen temporal que estimule la diligencia de los titulares de la garantía. Ese régimen temporal es diverso: plazos preclusivos, establecidos por la ley o por el tribunal -dotado de un potestad discrecional o dependiente de conceptos jurídicos indeterminados-; momentos procesales en los que las partes, que deberán haber sido suficientemente preavisadas, deberán realizar determinadas aportaciones.

La sujeción a los requisitos legales de la actividad procesal de las partes comprende otros requisitos que no tiene que ver con el régimen temporal del proceso, como, por ejemplo, el de que aquella actividad deba o pueda ser dirigida por un profesional del Derecho, por un abogado. Si sólo se trata de que la parte puede optar por encargar esa dirección, en vez de actuar ella misma, sin duda la justificación es la mejor protección de la posición procesal de la parte, que, atendido el carácter técnico-jurídico del proceso y de su objeto, elige encomendar la defensa de su posición a quien es conocedor de esa técnica. Si, diferentemente, esa dirección se impone como norma imperativa, la justificación ya no podrá buscarse en los intereses de las partes, sino en un interés público de que la actividad de parte se realice directamente por expertos en técnica jurídica. En ambos supuestos, la actuación de abogado plantea problemas respecto de la garantía de igualdad de las partes.

\footnotetext{
${ }^{19}$ Sobre este contenido de la garantía de contradicción: TEDH (Sección 3a), sentencia de 6 diciembre 2007, Caso Súsanna Rós Westlund contra Islandia; TEDH, sentencia de 24 febrero 1995, Caso Mc Michael contra Reino Unido. Y para la jurisprudencia del TC español, PıCó, Las garantías, cit. nota n. 9, pp. 95-96.

${ }^{20}$ Rosemberg; Schwab, Zivilprozessrecht, cit. nota n. 17, p. 430; Phole, en Stein-Jonas, Kommentar, cit. nota n. 1, p. 660; Trocker, Processo, cit. nota n. 2, pp. 510-517; Almagro, "Garantías", cit. nota n. 10, pp. 33-34; Ortells, Introducción, cit. nota n. 1, p. 73.
} 


\section{b) La garantía de contradicción y las formas del procedimiento}

La garantía de contradicción puede ser respetada cualquiera sea la forma del procedimiento, pero estas diferentes formas deben ser reguladas de modo que ese resultado pueda ser conseguido.

Es común a todas las formas -como se apuntó más arriba- la efectividad del acto de comunicación por el que se llama al demandado al proceso y la previsión de plazos suficientes para la preparación de las aportaciones de las partes.

Contando con lo anterior, específicamente en un procedimiento escrito las formas de puesta en conocimiento son el traslado de los escritos de la contraparte, la entrega temporal de los autos y la puesta de manifiesto de los mismos en la secretaría del tribunal por un cierto plazo.

La realización de la garantía de contradicción en un procedimiento oral se produce de modo más ágil que en uno escrito, al menos a primera vista. La simultánea presencia de las partes en las sesiones del juicio en el que se introduce todo el material procesal, permite una inmediata toma de conocimiento y una también inmediata posibilidad de intervención. No obstante, para que esto sea así y, al mismo tiempo, la parte no vea mermada la eficacia de su defensa por tener que reaccionar ante cuestiones que la sorprendan, esa actividad oral ha de haber sido suficientemente preparada con anterioridad. Por otro lado, pueden plantearse problemas específicos de respeto a la contradicción en un juicio oral, respecto a aquellos materiales que por su naturaleza -práctica de pruebas por auxilio judicial o por delegación- no han sido producidos en la propia audiencia; en estos casos se impone la lectura de la documentación u otro modo de indicación formal de que dichos materiales serán tenidos en cuenta para dictar la sentencia, con el objeto de llamar la atención de las partes y provocar sus manifestaciones al respecto.

\section{La garantía de la contradicción (sigue): el derecho a la prueba}

La garantía de contradicción comprende -como se anticipó- el derecho a influir en el resultado del proceso mediante la prueba. En Derecho español este alcance de la garantía se proclama expresamente por el art. 24.2 CE: "derecho a utilizar los medios de prueba pertinentes para su defensa".

El reconocimiento constitucional de este derecho no significa que el legislador ordinario no pueda regular su ejercicio, estableciendo requisitos de los que depende la admisión por el tribunal de los medios de prueba propuestos por las partes, así como disponiendo las modalidades de intervención de éstas en la práctica de los medios de prueba. La aplicación de este régimen jurídico compete el tribunal que dirige el proceso. Pero, aunque el régimen legal y los actos judiciales de aplicación no sean fácilmente considerados contrarios a la 
norma constitucional antes mencionada, existe un núcleo irreductible cuya afectación podría motivar pronunciamientos de inconstitucionalidad o estimaciones de amparo por violación del derecho fundamental. ${ }^{21}$

La relación entre el derecho a la prueba-como componente de la garantía de contradicción-y la forma de la actividad procesal -principal objeto de nuestra atención- aconseja distinguir los diversos actos necesarios para la realización de la prueba, para examinar si el respeto esencial a ese derecho impone que estos actos deban sujetarse a formas determinadas.

Los primeros actos -en el orden lógico- son los de proposición y admisión de medios de prueba, y, en su caso, los de preparación de la práctica de los mismos. El derecho a la prueba no experimentará ningún menoscabo en su esencia por el hecho de que la forma de esta clase de actos sea escrita u oral. No obstante, cabe apuntar que la utilización de la segunda forma puede dificultar, salvo que vaya acompañada de una adecuada documentación, la actividad de preparación de la práctica de algunos medios de prueba (citaciones judiciales, requerimientos de aportación de documentos o de otros objetos).

La actividad que subsigue es la de práctica de los medios de prueba. Desde el punto de vista de la mayor calidad de los resultados probatorios, por una más perfecta valoración de la prueba practicada, podría decirse que para la práctica de los medios de prueba consistentes en declaraciones personales -incluso para la prueba pericial, por la posibilidad de obtener explicaciones complementarias o aclaratorias de un informe escrito- resulta más adecuada la forma oral. Pero ahora no se trata de apreciar la mejor adecuación, sino de comprobar si esa clase de medios de prueba sólo tolera una práctica según las reglas de la oralidad. La conclusión ha de ser negativa porque, en esencia, lo que importa es aprovechar la capacidad informativa de la parte o del testigo (o del perito), lo que -particularmente si concurren circunstancias que no facilitan la oralidad- puede obtenerse suficientemente mediante una documentación fehaciente de la declaración del sujeto de la prueba.

5. La garantía de la igualdad de las partes en el proceso: igualdad de las posiciones jurídicas procesales y condiciones reales de igualdad

Por dos razones es conveniente puntualizar ahora que nuestras reflexiones se centran en las garantías y en las formas del procedimiento del proceso de declaración, y no en las del proceso de ejecución. Primera, porque respecto del proceso de ejecución la forma procedimental de la oralidad -que constituye objeto principal de nuestra atención- no es adecuada. Segunda, porque sólo

${ }^{21}$ PICó, Las garantías, cit. nota n. 9, pp. 143-151; PICÓ i Junor, J., El derecho a la prueba en el proceso civil, J. M. Bosch Editor S.A., Barcelona, 1996, pp. 45-156. 
en el proceso de declaración las garantías que hemos considerado hasta ahora van acompañadas de la garantía complementaria de la igualdad. ${ }^{22}$

La garantía de la igualdad se formula, en algunos de los textos normativos básicos reseñados en el apartado II, de modo muy expreso (art. 10 DUDH, art. 14.1 PIDCP), mientras que en otros textos hay que entenderla incluida en la referencia a que la audiencia debe ser "equitativa" (art. 6.1 CEDH, art. 47 CDFUE) o a que el proceso, al que se tiene derecho, debe ser un proceso "con todas las garantías" (art. 24.2 CE) o "con las debidas garantías" (art. 8.1 CADH, art. $49 \mathrm{CV})$.

a) Igualdad en la ley procesal y condiciones reales de igualdad en el proceso

La garantía de la igualdad tiene, en primer lugar, un significado que, en algún momento, solía calificarse de jurídico-formal, pero que basta considerar como jurídico. En segundo término, más allá de este significado, también es relevante examinar si las condiciones reales, socioeconómicas, en las que se halla la persona a la que el ordenamiento reconoce la igualdad jurídica, pueden incidir negativamente en la eficacia de ésta y de qué modo puede corregirse esa incidencia.

La igualdad de las partes implica, en el primer aspecto mencionado, que toda persona tenga iguales posibilidades de acceso a los tribunales, para disponer de una chance igual de reconocimiento y tutela de los derechos e intereses que alegue; es decir: igualdad de trato en cuanto a la concesión de los derechos de acceder al proceso, formulando pretensiones de tutela, y de defenderse frente a las mismas.

Requiere, después, a proceso iniciado, que las partes, situadas ante un juez imparcial, tengan iguales posibilidades y derechos, estén sometidas a las mismas cargas y se reparta entre ellas de modo igualitario el riesgo de resultado del proceso. ${ }^{23}$

Esta igualdad es una garantía para que se dicte una correcta resolución, y completa la garantía de la contradicción, dirigida al mismo objetivo. En efecto, si a una parte se le impidiera o restringiera la exposición y defensa de su posición jurídica, sólo se atendería -o se atendería preferentemente- a la

\footnotetext{
${ }^{22}$ Una ampliación de estas consideraciones en Ortells Ramos, M., y otros, Derecho procesal civil, Aranzadi-Thomson Reuters, Cizur Menor, 2009, pp. 684-686.

${ }^{23}$ Bötticher, E., Die Gleichheit for dem Richter, Hamburg, 1961, pp. 9-20; Phole en Stein-Jonas, Kommentar, cit. nota n. 1, p. 649; Prieto-CAstro, L., Tratado de Derecho Procesal. Derecho procesal civil, II, Madrid, 1953, p. 8. Sobre desigualdades jurídicas de las partes en el proceso véanse: TEDH (Gran Sala), sentencia de 7 junio 2001, Caso Kress contra Francia; TEDH, sentencia de 24 febrero 1995, Caso Mc Michael contra Reino Unido.
} 
posición de la otra parte, lo que obstaculizaría necesariamente el equilibrio de la resolución. ${ }^{24}$

El segundo aspecto apuntado al principio -es decir: las condiciones reales, socioeconómicas, que inciden en el efectivo aprovechamiento de las posibilidades reconocidas en términos de igualdad jurídica-, plantea problemas de diferente complejidad:

$\left.1^{\circ}\right)$ El problema más acotado deriva del carácter preceptivo de la actuación de un profesional del Derecho, de un abogado, para defender directamente ante el tribunal la posición procesal de las partes. Es cierto que esta actuación, por un lado, contribuye a reducir la incidencia de las desigualdades naturales de las partes. Pero, por otro lado, constituye la ocasión para que incida la desigualdad real, socioeconómica, porque no todos los justiciables disfrutan de una situación económica que les permita atender a la retribución de estos profesionales.

En los supuestos en que la actuación del abogado no es preceptiva, sino facultativa, el problema subsiste si una parte decide actuar mediante abogado, y la contraparte no puede decidir libremente lo mismo, por razones de incapacidad económica.

Para cumplir este aspecto de la garantía de igualdad ya no basta con una determinada ordenación jurídica, sino es necesaria la prestación de un servicio de defensa jurídica gratuita -que, obviamente, también deberá ser jurídicamente regulado- ${ }^{25} \mathrm{El}$ derecho a este servicio viene establecido, en el máximo nivel normativo, por varios textos de los que hemos reseñado en el apartado II (arts. 119 CE, 26 CV y 47 CDFUE).

$\left.2^{\circ}\right)$ Mucho más compleja es la apreciación de que el conjunto de la ordenación de un proceso civil puede situar en estado de desigualdad real a la parte económicamente menos potente. ${ }^{26}$ Un procedimiento escrito, complejo en su desarrollo -por ejemplo, a causa de incidentes y recursos interlocutorios que posibilitan prolongar su duración-, restrictivo con la tutela cautelar y con las posibilidades de ejecución provisional, favorece a la parte económicamente fuerte, que tiene mayor capacidad de resistencia frente a los mencionados inconvenientes. Eso incide en la igualdad real, tanto si esa parte ha de demandar, como si ha de ser demandada: en el primer caso puede aguantar mejor esos inconvenientes; en el segundo, su mayor capacidad de resistencia puede retraer la acción de la parte económicamente débil que precise demandar.

\footnotetext{
${ }^{24}$ KeRN, E.; WOLf, M., Gerichtsverfassungsrecht, München, 1975, p. 181.

${ }^{25}$ Ortells, Introducción, cit. nota n. 1, pp. 177, 181-182; Picó, Las garantías, cit. nota n. 9, pp. 59-60; BONET, "El acceso", cit. n. 11, pp. 74-77.

${ }^{26}$ Cappelletti, M., Giustizia e società, 1972, pp. 226, 237-266; Trocker, Processo, cit. nota n. 2, pp. 295 299, 308; KERN, Gerichtsverfassungsrecht, cit. nota n. 24, pp. 177-178, 182; WASSERMANN, R., Der soziale Zivilprozess, Neuwied-Darmstad, 1978, pp. 188-192; OrTelLs, Introducción, cit. nota n. 1, pp. 181-182.
} 


\section{b) Igualdad de las partes y formas del procedimiento}

Volvamos, de nuevo, a la cuestión de si una garantía del proceso -ahora, la de igualdad de las partes- impone una determinada forma del procedimiento.

De entrada debo apuntar que no me parece correcto responder a esta cuestión desde la perspectiva de la apreciación compleja de que determinada forma procedimental (la escrita) sería poco compatible con la igualdad real de las partes. La forma procedimental adecuada para un proceso de declaración no puede determinarse atendiendo a una sola de las garantías que deben ser respetadas, sino al conjunto de las garantías y, como después veremos, también a razones de eficiencia del proceso.

Más justificado está analizar si existe una implicación necesaria entre igualdad de las partes y formas de los actos en el sentido de que los pares dialécticos de los actos de parte (por ejemplo: demanda-contestación, interposición de recurso-oposición al mismo) deban estar sujetos a la misma forma.

Puede ser útil descender a un ejemplo concreto. En una reforma de la casación civil española -la de 1992- fue eliminada la vista preceptiva ante la Sala y se estableció la forma escrita para el acto de oposición al recurso. Hubo autores que justificaron esta reforma en la más perfecta realización de la igualdad entre las partes, porque, con la escritura, el acto de oposición adquiría las ventajas de la reflexión, mayor precisión y fijeza que, hasta el momento, sólo tenía el acto de interposición del recurso. ${ }^{27}$

En mi opinión, lo que afecta a la esencia de la igualdad es tener una oportunidad de respuesta efectiva ante el tribunal frente al acto de la contraparte. El componente psicológico, que subyace a la apreciación del párrafo anterior, es difícilmente ponderable para concluir si resulta afectada la esencia de la igualdad. En efecto, analizando esa misma reforma, otros juristas con buen conocimiento de la práctica judicial, apuntaron, por el contrario, que la forma oral era más ventajosa, porque permitía constatar que el conjunto de los magistrados de la Sala adquirían conocimiento de los materiales del recurso, evitando el riesgo de que ese conocimiento quedara limitado, de hecho, al magistrado ponente. ${ }^{28}$

\footnotetext{
${ }^{27}$ Martínez-Calcerrada y Gómez, L., "Principio inspirador de la nueva legalidad. Exposición de motivos", en La nueva casación civil. Estudio de la Ley 10/1992, de 30 de abril, reforma de los procesos civiles, Civitas, Madrid, 1993, pp. 129-130; Gullón, "Algunas observaciones sobre la reforma del recurso de casación", en la misma obra antes citada, pp. 176-177; GonzÁlez-Cuéllar SerRano, N., "El recurso de casación", en Gimeno Sendra (Dir.), Los recursos en el proceso civil, Tirant lo Blanch, Valencia, 1995, pp. 605-606.

${ }^{28}$ Serra D., M., "Del recurso de casación", en Montero; Serra, La Reforma de los Procesos Civiles. Comentario a la Ley 10/1992 de Medidas Urgentes de Reforma Procesal, Editorial Civitas, 1993, pp. 282-283; AlmaGro, "Luces y sombras del recurso de casación civil reformado", en MARTínez-CALCERRADA, La nueva casación, cit. nota n. 27 p. 150.
} 


\section{La garantía de la publicidad}

Es sabido que la garantía de la publicidad significa que el procedimiento debe ser regulado de modo que el público en general -no sólo las partes, cuyo derecho a conocer los contenidos procesales forma parte de la garantía de contradicción- pueda adquirir conocimiento del desarrollo del proceso y de su contenido.

En muchos de los textos normativos fundamentales reseñados en el apartado II, la garantía de la publicidad se establece con independencia de que, en el mismo texto, se haga o no una opción por una determinada forma del procedimiento (arts. 10 DUDH, 14.1 PIDCP, 6.1 CEDH, 47 CDFUE). En otros textos, sin embargo, la garantía de la publicidad se formula junto con una opción matizada por la oralidad procedimental (arts. 24 y 120 CE) o con una opción definida por esa forma (arts. 26 -justicia transparente-y, principalmente, $257 \mathrm{CV}$ ).

Por la naturaleza de las cosas la publicidad general es difícilmente practicable en un procedimiento escrito. La antigua LEC española de 1881 establecía la publicidad para las diligencias de prueba y para las vistas (art. 313). Salvo en el caso de las vistas -que, además, en muchos casos tenían un contenido simplemente conclusivo, no de producción de los materiales relevantes para la fundamentación de la sentencia- podía dudarse de la efectividad de la norma, porque la dispersión temporal con la que se practicaban las diversas pruebas hacía difícil que el público pudiera presenciar el conjunto de la actividad probatoria.

Por el contrario, la oralidad implica la posibilidad práctica de realizar el principio de publicidad general, porque la presencia del público en las vistas permite, dado el contenido de éstas, formarse una noción suficiente del asunto litigioso y de los datos y medios de prueba importantes para la resolución del mismo.

Este diferente grado de compatibilidad entre la publicidad y las dos formas procedimentales básicas conduce a que se establezca una dependencia muy fuerte entre publicidad y oralidad del procedimiento, en el sentido de que la garantía de la publicidad sólo podría ser satisfecha mediante un procedimiento oral. ${ }^{29}$

\footnotetext{
${ }^{29}$ Así, en el contexto del Derecho alemán, GoHm, Ch., Massnahmen zur Beschleunigung und Konzentration im neuen spanischen und deutschen Zivilprozess, Peter Lang Verlag, Frankfurt a. M., 2004, pp. 168-169. En la jurisprudencia del TEDH deben ser consideradas las sentencias de 29 septiembre 1999, Caso Serre contra Francia; 15 diciembre 2005 (Sección 3a), Caso Hurter contra Suiza; 20 mayo 1998, Caso Gautrin y otros contra Francia. Del análisis de estas sentencias no se deduce que el TEDH entienda que los materiales procesales -en los casos se trataba, en realidad, de procedimientos disciplinarios- deban ser introducidos necesariamente en una audiencia oral, sino más bien que, en el supuesto de esa audiencia, esté prevista por las reglas de procedimiento, la misma debe celebrarse con publicidad, salvo que concurran las excepciones del art. $6 \mathrm{CEDH}$.
} 
No obstante, sería erróneamente simplificador entender que la garantía de la publicidad orienta por sí sola la decisión legislativa sobre la forma del procedimiento. Dejando aparte que puede haber oralidad sin publicidad -en los supuestos previstos por las normas del rango adecuado-, y publicidad sin oralidad -con la técnica, ciertamente engorrosa, de un derecho general de acceso a la documentación judicial; en ocasiones mediante la publicación de algunos actos (por ejemplo, las sentencias)-, las etapas procedimentales orales -con la publicidad facilitada al máximo- coexisten con actividades escritas preparatorias - pero no por ellos menos importantes, porque son imprescindibles para la realización de otras garantías fundamentales- y excepcionalmente sustitutivas de actividades orales -sustitución con la que también se persigue preservar otras garantías fundamentales-.

\section{LAS FORMAS DE LOS PROCEDIMIENTOS JUDICIALES: UN RECIENTE PANORAMA DEL DERECHO COMPARADO}

Adoptamos, ahora, otra perspectiva: la de aproximarnos, como mínimo, a cómo resuelven los ordenamientos actuales la cuestión de las formas de los procedimientos judiciales. Nos servirán de gran ayuda para esto los recientes trabajos de la Asociación Internacional de Derecho Procesal, en el coloquio internacional celebrado en Valencia (España) en noviembre de 2008, precisamente sobre el tema general "Oralidad y escritura en un proceso civil eficiente" ${ }^{30}$

Indicaba Calamandrei que "según la forma de los actos procesales singulares que constituyen la serie y según el orden y la relación en que se suceden, el proceso puede asumir diversas figuras típicas". Lo que caracteriza esa tipicidad es el predominio del elemento oral o del escrito, que viene a convertirse en el primer problema del procedimiento. ${ }^{31}$

También es antigua la constatación de que ni los sistemas procedimentales vigentes, ni las pretensiones de reforma se orientan hacia el establecimiento en su estado puro de alguna de las formas citadas, sino que más bien reflejan y tienden a una combinación de formas orales y escritas. "El problema de la oralidad y de la escritura en el procedimiento se plantea a menudo como un

\footnotetext{
${ }^{30}$ Las ponencias generales, los informes nacionales y las abundantes comunicaciones aportadas, han sido publicadas en CARPI, F.; Ortells Ramos, M., Eds., Oralidad y escritura en un proceso civil eficiente I Oral and Written Proceedings: Efficiency in Civil Procedure, tomos I y II., Asociación Internacional de Derecho Procesal - Universitat de València, Valencia, 2008.

${ }^{31}$ La cita de Calamandrei, P., corresponde a Calamandrel, P., Instituciones de Derecho Procesal según el nuevo Código I, cito por la traducción editada en BB.AA, Ediciones Jurídicas Europa-América, 1962 , p. 382. La incidencia de los elementos orales o escritos como determinante de la calidad del procedimiento la menciona ChIOvenda, G., Instituciones de Derecho procesal civil, III, Traducción de Gómez Orbaneja, Ed. Revista de Derecho Privado, Madrid, 1936, p. 154.
} 
problema de predominio o de coordinación y no de exclusión total" ${ }^{32}$ Pasado el tiempo, se continúa manteniendo por la doctrina procesal que la cuestión de las formas procedimentales es cuestión de combinación y de predominio. ${ }^{33}$

Planteado el problema de la caracterización oral o escrita del procedimiento como una cuestión, no de exclusividad, sino de combinación y predominio de formas, se ofrece al observador un panorama muy amplio de modelos procedimentales. Estos modelos pueden ser calificados como escritos u orales según la forma de los actos que predomine y la función de los actos que se realicen en cada una de las formas. La sola existencia de un debate oral no convierte en oral un procedimiento porque, aparte de su irrelevancia cuantitativa comparada con la forma escrita en los demás actos, cumple una función secundaria respecto a la aportación contradictoria del material procesal que consta por escrito y respecto al cual se limita a ser un resumen crítico y conclusivo. De igual modo la utilización de la escritura no desnaturaliza un procedimiento oral, si el carácter de los actos escritos es el de preparación de la vista oral o el de documentación de lo que en ella acaece y haya de ser constatado por su relevancia para posteriores instancias o recursos.

Ni el significado literal de los términos oralidad y escritura, ni la observación de que en los diversos ordenamientos estas formas se presentan combinadas, proporcionan, sin embargo, una idea suficiente de los criterios generales de ordenación del procedimiento. Oralidad y escritura no son principios individuales, sino que designan sendos sistemas integrados por series respectivas de principios entre sí coordinados. La doctrina alemana se ha orientado, desde luego sin olvidar la interconexión que entre ellos existe, al estudio asilado de cada uno de los principios, profundizando en su individualidad conceptual. ${ }^{34}$ La doctrina italiana, por el contrario, ha insistido preferentemente en que oralidad y escritura designan un sistema orgánico de principios procedimentales; y, así, pudo decir Denti que "en efecto, el predominio de la discusión oral del pleito, con la conexa función meramente preparatoria y de documentación de los escritos, sólo tiene sentido si el juez que ha de decidir la controversia es el mismo que ha asistido al desarrollo de la prueba y ha entrado en relación directa con las partes, si el tratamiento del pleito se desenvuelve en audiencias cercanas, de tal modo que permita la valoración directa de las actividades

\footnotetext{
${ }^{32}$ Cappelletti, M., Procédure orale et procédure écrite, Giuffrè, Milano-New York, 1971, p. 12

${ }^{33}$ Así, KıP, H. G., Das sogennante Mündlichkeitsprinzip, Köln-Berlin, 1952, p. 152; Arens, P., Mündlichkeitsprinzip und Prozessbeschleunigung im Zivilprozess, Berlin, 1977, p. 47; LEIPOLD. D., "Oral and written elements within the introductory phase of civil procedure", pp. 76-78; TARUFFO, M., "Orality and writting as factors of efficiency in civil litigation", pp. 203-204; PeYrano., J. W., "La prueba entre la oralidad y la escritura", p. 152. Ver las tres obras precedentes en CARPI, ORTELLS, Oralidad y escritura, v. I, cit. nota n. 30 .

${ }^{34}$ Grunsky, Grundlagen, cit. nota n. 14, p. 213; Arens, Mündlichkeitsprinzip, cit. nota n. 33, p. 27.
} 
procesales por parte del juez". ${ }^{35}$ Esta misma orientación ha sido seguida por la doctrina española. ${ }^{36}$

Solamente del último modo referido puede adquirirse un conocimiento acertado del modelo procedimental. La forma oral, predominante en el conjunto de actos procesales, se concreta en la inmediación en cuanto a la práctica de la prueba, la eficacia de la oralidad y la inmediación exigen la concentración y todo ello conduce a la facilitación de la publicidad general. Si es preponderante la forma escrita, se requiere una cierta dispersión de los actos procesales -que, además, tiende a aumentar-, si la inmediación está prescrita deviene ineficaz a causa de la dispersión, deduciéndose del conjunto la dificultad o la limitación de las posibilidades de publicidad.

Atendidas estas consideraciones ¿Con qué nos encontramos al revisar -obviamente en líneas generales- el estado normativo de esta materia en el Derecho comparado?

Por un lado, podemos observar cómo se combinan las formas en un mismo procedimiento, el más común o general en cada ordenamiento. Por otro lado, es notable y debe destacarse otro modo de combinación, consistente en que, en un mismo ordenamiento, coexisten procedimientos predominantemente orales y predominantemente escritos, previstos unos y otros para ser aplicados a diferentes clases de litigios.

\section{Componentes de escritura y de oralidad en un mismo procedimiento}

Cada uno de estos dos componentes está diferentemente presente en distintas etapas del proceso de declaración. La intensidad y las razones de esa diferencia son variadas.

En la etapa inicial del proceso, predomina la forma escrita de los actos de demanda y de contestación, y hay manifestaciones de la sujeción de esa forma escrita a modelos que facilitan el cumplimiento de los requisitos. ${ }^{37}$

\footnotetext{
${ }^{35}$ DentI, V., "L'oralità nelle riforme del processo civile", en Processo civile e giustizia sociale, Milano, 1971, p. 123.

${ }^{36}$ FaIrén Guillén, V., "Elaboración de una doctrina general de los principios del procedimiento", en Estudios de Derecho Procesal, Madrid, 1955, pp. 265 y ss.; Prieto-Castro, "Precisiones", cit. nota n. 10, pp. 78 y ss.; ORTELLS, Introducción, cit. nota n. 1, pp. 228-237.

${ }^{37}$ LEIPOLD, "Oral and written elements", cit. nota n. 33, pp. 58-59, 62; véanse, también, los informes nacionales de España: Armengot, Alicia, "La fase introductiva y el contrato Procesal. Informe Nacional", pp. 225-227, 228-230; Inglaterra y Gales: EINHAus, Stefan, "The introductory phase and the procedural contract - England and Wales", pp. 241-242, 243-244; Japón: Honma, Manabu, "The preliminary phase an the trial agreement in Japan", pp. 254, 255; Corea del Sur: JunGHOO Oh, "Mündliche und schriftliche Elemente bei del Klageerhebung nach der koreanischen Zivilprozessordnung", pp. 263-264, 268; Grecia: MANIOTIS, Dimitrhe N., "Some remarks concerning the pre-trial stadium and the proeceeding before the court according to the greek code of civil procedure", pp. 269; USA: Reinhard, Jakob, "Civil Procedure in the USA", pp. 281-282; Latinoamérica: TAVOlarI Gorcoolea, Pía, "La fase introductiva y el
} 
La forma oral para uno y otro de estos actos iniciales está excepcionalmente prevista -para asuntos de pequeña cuantía y con la finalidad de superar dificultades culturales de acceso a la justicia-, pero el acto es documentado en la oficina del tribunal y, además, atendido el uso efectivo de esta forma excepcionalmente autorizada, los autores coinciden en que su utilización es mínima, salvo en China. ${ }^{38}$

La etapa preparatoria del acto del juicio, que subsigue a la demanda y la contestación es muy diversificada desde el punto de vista de la forma. ${ }^{39}$ En algunos ordenamientos predomina la oralidad -en el sentido de que la preparación se lleva a cabo en una audiencia-;40 en otros la preparación es escrita; ${ }^{41}$ en otros, por fin, la preparación puede ser escrita -con posibilidad de convocar audiencias- o escrita u oral según determinadas características del asunto litigioso. ${ }^{42}$

La etapa del proceso destinada, principalmente, a practicar las pruebas sobre cuyos resultados se fundará la sentencia, constituye el auténtico punctum dolens de la elección de las formas apropiadas para el procedimiento.

Esa especie de patetismo ${ }^{43}$ que envuelve el tema de las formas procedimentales para esta etapa procesal presenta varias manifestaciones, que pueden resumirse en las siguientes constataciones:

$1^{\text {a) }}$ Continúa considerándose un objetivo apreciable de política jurídica procesal el de que los medios de prueba personales, principalmente, ${ }^{44}$ sean

contrato procesal en el proceso civil latinoamericano", pp. 286-287, 288; China: HonglianG, Wang, "Civil pre-trial procedure in China", pp. 296, 298. Ver todos en CARPI, ORTells, Oralidad y escritura, v. I, cit. nota n. 30.

38 Informes nacionales de Grecia: Maniotis, "Some remarks", cit. nota n. 37, pp. 274, 277; China: HONGliANG, "Civil pre-trial", cit. nota n. 37, pp. 298-300.

${ }^{39}$ LEIPOLD, "Oral and written elements", cit. nota n. 33, pp. 64-74.

${ }^{40}$ Informes nacionales de España: ArmenGot, "La fase introductiva", cit. nota n. 37, pp. 232-233, 234235; y de Latinoamérica: TAVOLARI, "La fase itroductiva", cit. nota n. 37, pp. 289-291, aunque sus referencias se hacen sólo a algunos Códigos y, en algún caso, a proyectos de Códigos.

${ }^{41}$ Informes nacionales de Grecia: MANIOTIS, "Some remarks", cit. nota n. 37, pp. 274, 277; China: HONGlianG, "Civil pre-trial", cit. nota n. 37, pp. 298-300.

${ }^{42}$ LEIPOLD, "Oral and written elements", cit. nota n. 33, pp. 65-66; véanse, también, los informes nacionales de Inglaterra y Gales: EINHAus, "The introductory", cit. nota n. 37, pp. 244-245; Japón: Honma, "The preliminary", cit. nota n. 37, pp. 257-258; Corea del Sur: JunGHOO Oh, "The preliminary", cit. nota n. 37, p. 268; USA: ReinHARD, "Civil Procedure", cit. nota n. 37, pp. 282-283.

${ }^{43}$ Quiero resaltar con esta expresión las tensiones que denotan la notable divergencia, que se detecta en esta materia, entre las previsiones normativas y la realidad aplicativa y la perceptible dificultad de realización de unos objetivos de política jurídica que, por lo general, se consideran plausibles.

${ }^{44}$ La apreciación podría extenderse a la prueba pericial, en cuanto a la explicación de un previo dictamen escrito, y a los medios audiovisuales, en cuanto sus contenidos son técnicamente idóneos para ser presentados con publicidad. 
practicados de modo concentrado, en una o varias audiencias inmediatamente previas a la emisión de la sentencia. ${ }^{45}$ No obstante, tampoco faltan reticencias frente a esta opinión, que no siempre están relacionadas -como es más frecuente- con la falta de medios necesarios para una efectiva realización de la oralidad en esta etapa, sino con objeciones esenciales. ${ }^{46}$

$2^{a}$ ) En algunos ordenamientos la oralidad ha acabado imponiéndose para esta etapa procesal. ${ }^{47}$

$3^{\mathrm{a}}$ ) No obstante, a pesar de aquel reconocido aprecio, lo que prevalece, en muchos ordenamientos, es la escritura -y esto significa, principalmente, dispersión de los actos de práctica y mediación-, aunque en algunos de ellos se ha previsto la oralidad para procesos sobre litigios de pequeña cuantía o que versen sobre determinadas materias (familia, relaciones laborales). ${ }^{48}$

$4^{a}$ ) Incluso si en un ordenamiento se ha optado por la oralidad para esta etapa, la concentración y la inmediación que se requieren para que esa opción sea efectiva suelen fallar porque faltan medios personales y materiales en la organización judicial -y esto, a su vez, por carencia de suficientes recursos presupuestarios- y por reticencias de los profesionales que actúan en el proceso. Esta quiebra puede producirse bien sea por simple divergencia entre la previsión normativa y el funcionamiento real del proceso, bien sea porque la ordenación normativa permite o no impide excepciones a favor de la escritura que, en la práctica, Ilegan a tener una amplia aplicación. ${ }^{49}$

$\left.5^{a}\right)$ En cualquier caso, merece ser destacada la general advertencia de que el éxito de la opción por la oralidad -concentración e inmediación- para esta etapa

${ }^{45}$ Taruffo, "Orality and writting", cit. nota n. 33, pp. 198-199; Peyrano, "La prueba", cit. nota n. 33, pp. 151-157. También los informes nacionales de Venezuela: Quintero TIRADO, M., "La prueba entre la oralidad y la escritura", p. 371, y Chile: TAVOları Oliveros, R., "La prueba entre la oralidad y la escritura", pp. 406-408. Ambos en Carpl, Ortells, Oralidad y escritura, v. I, cit. nota n. 30.

${ }^{46}$ Así TARuffo, "Orality and writting", cit. nota n. 33, cuando alude a los límites de la utilidad de interrogatorio cruzado y a la probable falta de aptitudes del juez para aplicar técnicas de psicología del testimonio; PeYrano, "La prueba", cit. nota n. 33, pp. 158-159, cuando hace referencia al desgaste físico y emocional de los jueces y a los riesgos de error por una valoración excesivamente rápida de la prueba.

${ }^{47}$ Véanse los informes nacionales para España: de Picó I JunOr, J., "El principio de oralidad en el proceso civil español", pp. 360-370; para Uruguay: SıмÓN, L. M., "La prueba entre la oralidad y la escritura", pp. 391-402; y para Perú: MONROY, J., "Relación sobre la prueba entre la oralidad y la escritura en el proceso civil peruano", pp. 333-341. Ver todos en CARPI, ORTELLs, Oralidad y escritura, v. I, cit. nota n. 30,

${ }^{48}$ Informes nacionales de Quintero, "La prueba", cit. nota n. 45, pp. 325-331; TAvolari, "La prueba", cit. nota n. 45, pp. 403-404, además de los autores que serán citados en la nota siguiente.

${ }^{49}$ TARUfFo, "Orality and writting", cit. nota n. 33, pp. 194-195, 197-198. Véanse, igualmente, los informes nacionales sobre Italia, BIAvATI, P., "Oral and written evidence in Italian civil procedure law", pp. 313323; sobre Argentina, OтеízA, E., "El fracaso de la oralidad en el proceso civil argentino", pp. 419-424; sobre México, de Ovalle Favella, J., pp. 427-428, 431. Todos en CARPI, Ortells, Oralidad y escritura, v. I, cit. nota n. 30; y sobre Venezuela, de QuiNTERO, "La prueba", cit. nota n. 45, pp. 371-389. 
del proceso, no sólo depende del voluntarismo legislativo, sino que requiere medidas organizativas idóneas y recursos personales y materiales suficientes, que, a su vez, sólo pueden conseguirse mediante las adecuadas dotaciones presupuestarias. ${ }^{50}$

\section{Procedimientos (predominantemente) escritos y (predominantemente) orales en un mismo ordenamiento}

Este segundo modo de combinación entre procedimientos escritos y procedimientos orales es la respuesta a un planteamiento muy razonable, ciertamente no es novedosa, pero tiene ante sí una amplia perspectiva de evolución y de perfeccionamiento. Se trata, en definitiva, de que las diferentes características de los litigios que acceden a los tribunales puedan determinar que sean más adecuados, para su tratamiento, procedimientos predominantemente escritos o predominantemente orales.

Poco antes ${ }^{51}$ apunté que esta ponencia deja expresamente al margen la forma procedimental idónea para la tutela judicial ejecutiva, porque es poco dudoso que la oralidad no es una forma que merezca ser considerada seriamente para la actividad ejecutiva. No me referiré, pues, a la diversidad procedimental que debe producirse, y normalmente se produce, entre proceso de ejecución y proceso de declaración, sino a la diversidad procedimental dentro de este último.

Ciertamente, no es nada nueva en los ordenamientos procesales. Una de sus manifestaciones más conocidas consiste en que la propia ley establezca la diversidad procedimental y los requisitos de los asuntos litigiosos que son relevantes para que deba ser seguido uno u otro procedimiento (con diverso predominio de la oralidad o de la escritura). ${ }^{52}$

Este razonable tratamiento plantea, de inmediato, el problema de cuáles deben ser los requisitos del asunto litigioso relevantes para asignarle uno u otro curso procedimental. La respuesta, muy frecuente -al menos de entrada- de que lo decisivo debe ser la cuantía del pleito, no siempre es acertada, y, de hecho, los ordenamientos que, en principio, parten de la misma, permiten matizarla. ${ }^{53}$

\footnotetext{
${ }^{50}$ Peyrano, "La prueba", cit. nota n. 33, pp. 157-159, y el informe nacional de Tavolari, "La prueba", cit. nota n. 45, pp. 403-410. También las aportaciones citadas en la nota inmediatamente anterior.

${ }^{51}$ Véase, más arriba, apartado II, 5.

${ }^{52}$ LeIPOLD, "Oral and written elements", cit. nota n. 33, pp. 63-64; TARUfFO, "Orality and writting", cit. nota n. 33, p. 203.

${ }^{53}$ LeIPOLD, "Oral and written elements", cit. nota n. 33, pp. 63-64; TARUFFO, "Orality and writting", cit. nota n. 33, p. 203; y los informes nacionales de Einhaus, "The introductory", cit. nota n. 37, pp. 247-248, y Pasanante, L., "Oralità e scritura nel processo civile inglese" en CARPI, Ortells, Oralidad y escritura, v. I, cit. nota n. 30, pp. 434-436.
} 
Es más acertado conceder relevancia a la complejidad del litigio; más específicamente, a las necesidades de debate que genera y a la calidad de las pruebas que deben ser preparadas y practicadas. ${ }^{54}$

Ciertamente, este modo de entender los requisitos relevantes tiene muchas aplicaciones, pero, a título de ejemplo, apunto dos muy claras:

$1^{\text {a) }}$ La reclamación de una deuda dineraria o de otra prestación suficientemente definida en cuanto a su objeto y exigibilidad, mediante un procedimiento de estructura monitoria, puede alcanzar su objetivo mediante una actividad procesal exclusivamente escrita. ${ }^{55}$

$2^{\mathrm{a}}$ ) El concreto devenir de un proceso, sujeto a las reglas del procedimiento común, puede conducir a que la oralidad tenga, justificadamente, una aplicación muy limitada. Por ejemplo, en la LEC española de 2000, si las partes, en la audiencia previa del juicio ordinario, manifiestan su conformidad sobre los hechos y limitan su controversia a la apreciación jurídica de los mismos, o si, manteniendo la controversia sobre los hechos, limitan su proposición probatoria a los documentos y dictámenes periciales aportados en demanda y contestación, y no impugnados, sólo resta dictar sentencia, sin que deba celebrarse el juicio o audiencia principal (arts. 428.3 y 429.8 LEC española 2000).

En fin, si esas características de complejidad del caso representan el más acertado indicador para asignarle un procedimiento adecuado (predominantemente oral o predominantemente escrito), como la diversa complejidad de los casos litigiosos -aunque puedan establecerse estándares- depende de la realidad concreta de los mismos, resulta que un perfeccionamiento de esta solución debe tender a que se le atribuyan al juez potestades discrecionales para, siempre previa contradicción de las partes, determinar el trámite procedimental al que debe someterse el tratamiento del asunto. ${ }^{56}$

\section{LAS GARANTÍAS PROCESALES FUNDAMENTALES COMO MARCO Y LA EFICIENCIA DEL PROCESO} CIVIL COMO CRITERIO PARA LAS OPCIONES LEGISLATIVAS SOBRE LAS FORMAS DEL PROCEDIMIENTO

En el apartado III de este trabajo nos propusimos ilustrar sobre que las garantías procesales fundamentales ni imponen, ni excluyen, en términos

\footnotetext{
${ }^{54}$ Véanse, además de los autores y lugares citados en la nota anterior, TARUFFO, "Orality and writting", cit. nota n. 33, pp. 193-194; informe nacional de BIAVATI, "Oral and written", cit. nota n. 49, p. 319; Ortells Ramos, M., "Entrevista sobre la reforma procesal civil en Chile", Boletín Jurídico del Ministerio de Justicia número 7 año 4, noviembre, 2005, pp. 42-44.

${ }^{55}$ Peyrano, "La prueba", cit. nota n. 33, p. 149, y el informe nacional de Otelza, "El fracaso", cit. nota n. 49, p. 415.

${ }^{56}$ Sobre esta orientación, en Derecho inglés, LeIPOLD, "Oral and written elements", cit. nota n. 33, p. 64; TARUFFO, "Orality and writting", cit. nota n. 33, pp. 203-204; y los informes nacionales de EINHAus, "The introductory", cit. nota n. 37, pp. 247-248, y BIAVATI, "Oral and written", cit. nota n. 49 , p. 322.
} 
absolutos, unas u otras formas para la actividad procesal, por más que, en algunos supuestos, puedan constatarse mayores afinidades (o rechazos) entre el contenido de algunas garantías y algunas formas procedimentales. En todo caso, las garantías funcionan como marco para las opciones sobre las formas de de los procedimientos, porque la diversidad de éstas en ningún caso podrá desconocer o menoscabar el contenido esencial de aquéllas.

Dentro de ese marco, un criterio razonable, aunque ciertamente genérico, para optar entre las diferentes combinaciones de formas procedimentales es el de la eficiencia del proceso, del proceso civil, en nuestro caso. La eficiencia del proceso expresa una relación entre el fin que se pretende conseguir con el proceso y el tiempo y el coste de las actividades que son necesarias para alcanzarlo. La apreciación de la eficiencia requiere partir de un grado de calidad aceptable en la consecución del fin del proceso, dado el cual la eficiencia de éste será mayor cuanto menor sea el tiempo destinado a conseguirlo y menor el coste, que -al menos en parte- depende también de la duración de la actividad procesal.

La introducción de este criterio de eficiencia puede considerarse indebida e innecesaria en el contexto de ordenamientos que cuentan con normas constitucionales que, con matices (art. 120 CE: el procedimiento será predominantemente oral) o casi sin ellos (art. 257 CV: las leyes procesales adoptarán un procedimiento oral), expresan la opción por un procedimiento oral. Ahora bien -y situándonos en el contexto más rígidamente acotado en esta materia, como lo es el del ordenamiento venezolano- cuando, al mismo tiempo, la Constitución impone un procedimiento oral (art. $257 \mathrm{CV}$ ) y que la justicia "sea expedita, sin dilaciones indebidas, sin formalismos o reposiciones inútiles" (art. $26 \mathrm{CV}$ ), que toda persona "tenga derecho a ser oída en cualquier clase de proceso, con las debidas garantías y dentro del plazo razonable determinado legalmente" (art. 49.1 CV), que las leyes procesales establezcan "la simplificación ... y eficacia de los trámites", adopten "un procedimiento breve", en el que "no se sacrificará la justicia por la omisión de formalidades no esenciales" (las tres últimas disposiciones acompañan a la de la oralidad en el art. $257 \mathrm{CV}$ ), resulta imprescindible introducir componentes de escritura que, sin negar la preponderancia de la oralidad, posibiliten el cumplimiento de los derechos fundamentales y de otras normas constitucionales. Aquéllos y éstas, como ya hemos apuntado y tendremos ocasión de profundizar, experimentarían menoscabo si las leyes no autorizaran determinados usos de la escritura. De modo que, respetando la preferencia de la oralidad, en estos ordenamientos no se excluye la necesidad de un criterio para determinar qué componentes de escritura pueden -o han de- acompañarla, y el criterio de la eficiencia del proceso cumple razonablemente ese papel. 
Una última dificultad para seguir razonando con base en el criterio de eficiencia, es la atinente a lo que podríamos Ilamar su "medición", porque razonar respecto de la eficiencia conduce inexorablemente a algún cálculo, que en nuestra materia sin duda no podrá ser matemático.

\section{El fin del proceso como referente para la apreciación de la eficiencia}

La primera manifestación de esa dificultad de "medición" viene dada por la determinación de cuál debe entenderse que es el fin del proceso civil, el resultado al cual es legítimo y debido que tienda el mismo.

Taruffo hacía notar recientemente esta dificultad y, simplificando, apuntaba una doble posibilidad: el proceso civil puede tener por finalidad una resolución de conflictos simplemente, o una resolución de conflictos mediante decisiones justas. La primera posibilidad se conforma con respetar un procedimiento, pero no confiere importancia, en la concepción del fin del proceso, al fondo y la calidad de la decisión final, de modo que hasta una decisión errónea o incluso ilegal se entiende que alcanza el fin del proceso, en cuanto pone fin a la disputa entre las partes. La segunda concepción del fin del proceso entiende, también, que con él se persigue poner fin al conflicto, pero empleando únicamente medios que se consideren justos, correctos, certeros y ecuánimes. De acuerdo con esto, la calidad de la resolución adquiere gran importancia, y, aunque no pueda garantizarse absolutamente su consecución, el instrumento procesal debe diseñarse para aproximarse el máximo a tal objetivo. ${ }^{57}$

Obviamente, la opción por una de estas dos posibilidades incide, decisivamente, en la apreciación de la eficiencia. Si se tratara solamente de restablecer la paz social, resolviendo los conflictos, la eficiencia dependería estrictamente de la minimización de los factores de tiempo y de coste. Sin llegar a la "optimización" de estos factores que se conseguiría haciendo depender el resultado del proceso de un juego de azar -paradigma que Rawls utilizó para ilustrar el concepto de la "justicia procesal pura" $-{ }^{58}$ sí que podríamos decir que la eficiencia dependería del tiempo y del coste imprescindibles para cumplir en esencia las garantías procesales fundamentales.

Si la opción debe ser la segunda -"paz con justicia", según la feliz expresión carneluttiana ${ }^{59}$ la apreciación se torna más compleja, porque la eficiencia no sólo está ligada a la menor duración y al menor coste, sino a una razonable calidad del resultado del proceso, lo que justifica -hace eficiente- determinada

\footnotetext{
${ }^{57}$ TARuffo, "Orality and writting", cit. nota n. 33, pp. 186-188.

${ }^{58}$ Rawls, J., Teoría de la Justicia, Traducción de González, M. D., Fondo de Cultura Económica, México, 1970, p. 109.

${ }^{59}$ Carnelutti, F., Sistema del Diritto Processuale Civile, I, Cedam, Casa Editrice Dott. Antonio Milani, Padova, 1936, p. 247.
} 
aplicación de tiempo y de dinero más allá de lo que vendría estrictamente impuesto por un mínimo respeto a las garantías procesales fundamentales.

En un reciente estudio empírico sobre la eficiencia de las formas del proceso se reconoce la esencial dificultad de medir la calidad de la justicia atendiendo al grado de acierto o corrección de las decisiones que se adoptan. Para una aproximación, el autor sugiere tener en cuenta otras variables relacionadas con esas características de la decisión, como, por ejemplo, las consideradas en la "Encuesta Global del Entorno de Negocios", que figura en la base de datos "Lex Mundi", tales como "los tribunales son justos e imparciales", "los tribunales son honestos y no corruptos", "Ios tribunales son coherentes", "la justicia es de calidad", y "se puede confiar en los tribunales". ${ }^{60}$

También podría apuntarse como método bastante objetivo y fiable para comprobar la calidad de los resultados de un proceso civil, los datos de confirmaciones frente a los de revocaciones/anulaciones de resoluciones que arroja el sistema de recursos, establecido por el propio ordenamiento para controlar la corrección de las resoluciones por tribunales de grado superior. ${ }^{61}$ Ciertamente estos datos no son significativos si se trata de recursos de naturaleza casacional -porque las diversas restricciones del recurso impiden que diversos posibles errores sean controlables-, pero tiene interés si se refieren a recursos ordinarios, cuya fundamentación no está legalmente limitada.

Sin perjuicio de considerar estos indicadores de calidad complementarios, prefiero atenerme a la idea de que la calidad del resultado del proceso civil consiste en: a) el acierto del juicio de hecho, lo que requiere suficientes posibilidades de aportación de hechos relevantes y de prueba de los mismos; b) el acierto del juicio de Derecho, que depende de la formación jurídica del juez y de una suficiente posibilidad de debate sobre los aspectos jurídicos. Condicionante común de estos aciertos lo es una suficiente posibilidad de reflexión en el momento del enjuiciamiento.

2. La incidencia de las diversas formas sobre la duración del proceso. Un apunte sobre el derecho a un proceso sin dilaciones indebidas, o en plazo razonable, y sobre el deber del Estado de establecer un sistema procesal que permita satisfacerlo

Algunas apreciaciones cuantitativas de esta incidencia ofrecen resultados contradictorios. Otro estudio, muy sugerente, Ilega a conclusiones que contrastan

\footnotetext{
${ }^{60}$ Ramos Romeu, F., "Forma del proceso y funcionamiento de la Justicia. Análisis de Derecho comparado", en CARPI, Ortells, Oralidad y escritura, v. II, cit. nota n. 10, p. 483.

${ }^{61}$ Efectivamente este dato es utilizado como indicio de calidad en la publicación La Justicia dato a dato, que, desde 2003 a 2008, está disponible respecto de la Justicia en España en el sitio web del Consejo General del Poder Judicial. En: http://www.poderjudicial.es [visitado el 15/03/2010].
} 
con apreciaciones no cuantitativas, aunque sí basadas en la experiencia y en la reflexión crítica de operadores jurídicos.

En cuanto a lo primero, Ilama la atención que la incidencia de la opción por un procedimiento predominantemente oral de la LEC española de 2000 sobre la duración del proceso, conduce a un autor a sostener que el actual procedimiento ordinario dura tanto como los antiguos procedimientos de mayor y de mayor cuantía, ${ }^{62}$ mientras que otro sostiene que los retrasos están lejos del alto grado de dilaciones indebidas bajo la antigua LEC. ${ }^{63}$

En cuanto al interesante estudio de Ramos Romeu, llega a la conclusión -es obvio que resultante de su planteamiento metodológico- de que el modelo oral tiene mejores medias que el escrito en cuanto a la rapidez del proceso y a la calidad de la justicia -apreciada con arreglo a unos indicadores a los que nos hemos referido más arriba-, y, también, que un modelo oral con componentes de escritura se aproxima más a las medias del modelo oral que a las del estrictamente escrito. ${ }^{64}$

Estas últimas conclusiones contrastan, en alguna medida, con observaciones, tal vez menos objetivadas, pero que se basan en la experiencia, y en la reflexión crítica sobre la misma, de juristas conocedores de la práctica judicial.

En esta línea se ha hecho notar:

$1^{\circ}$ ) La oralidad cambia el modo de distribución del tiempo de trabajo de los jueces, imponiéndoles -en algunas etapas del procedimiento (audiencias) - la necesidad de concentrar - tal vez por períodos largos- en exclusiva su actividad en un asunto ${ }^{65}$ lo que repercute en un retraso del conjunto de asuntos pendientes ante él. ${ }^{66}$ Esta misma observación se formula, más frecuentemente, de otro modo que conecta el factor "duración" con el factor "coste del proceso" -sobre el que volveremos en el siguiente apartado-: para que un procedimiento oral no origine importantes dilaciones indebidas, debe limitarse la carga de trabajo de los jueces que han de dirigirlo, lo que implica la necesidad de crear un mayor número de órganos jurisdiccionales. ${ }^{67}$

\footnotetext{
${ }^{62}$ VÁzQuez, "La oralidad y la escritura", cit. nota n. 10, p. 263.

${ }^{63}$ Informe nacional para España de Pıcó, "El principio", cit. nota n. 47, p. 367.

${ }^{64}$ Ramos, "Forma del proceso", cit. nota n. 60, pp. 486-487.

${ }^{65}$ Peyrano, "La prueba", cit. nota n. 33, p. 159; Biavatı, "Oral and written", cit. nota n. 49, p. 322, informe nacional sobre Italia; VÁzQUEZ, "La oralidad y la escritura", cit. nota n. 10, p. 264.

${ }^{66}$ A diferencia de lo que -según la ley o fuera (o contra) ella- ocurre en los procedimientos escritos, lo que debe hacer el juez en un procedimiento oral sólo puede hacerlo él -y no el personal auxiliar del tribunal, más o menos cualificado-, y, además, sin fragmentar su dedicación según el juez entienda que puede optimizar el rendimiento de su trabajo, sino concentrando esa dedicación en algunos momentos determinados.

${ }^{67}$ Informes nacionales de (España) Pıcó, "El principio", cit. nota n. 47, p. 369, de (Argentina) OTeízA, "El fracaso", cit. nota n. 49, pp. 423-424, de (Chile) TAvoları, "La prueba", cit. nota n. 45, p. 405.
} 
$2^{\circ}$ ) La oralidad para la recepción de (algunos) medios de prueba, que debe ir acompañada de inmediación y concentración, puede incrementar inútilmente la duración del proceso, en el caso que el material probatorio producido en la audiencia deba perder su validez para fundar la sentencia, debido a que, por cambios en la titularidad del órgano jurisdiccional, la sentencia debe ser dictada por un juez distinto al que presidió la audiencia. ${ }^{68}$

$3^{\circ}$ ) También respecto de la oralidad en la recepción de (algunos) medios de prueba, la pérdida -por razones distintas al cambio de titular del órgano- de la concentración y de la inmediación, de sus efectos ventajosos sobre la valoración de determinadas pruebas, podría conducir, también, a un inútil dispendio de tiempo si, en determinados supuestos, las audiencias debieran ser nuevamente

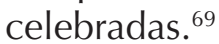

Teniendo presentes las garantías procesales fundamentales, el factor "duración del proceso" y la finalidad de que se alcance una sentencia acertada, se pueden avanzar algunos apuntes sobre las formas más adecuadas para actos, o conjuntos de actos, básicos en (la primera instancia del) procedimiento:

$\left.1^{\circ}\right)$ La forma del acto de iniciación del proceso, de proposición de su objeto, y del traslado de ese acto al demandado, está más influida por las garantías procesales fundamentales implicadas y por el objetivo de calidad de la sentencia, que por el factor "duración". La escritura es la forma más idónea, porque dota a este acto de una precisión y de una permanencia que son funcionales respecto de la delimitación de la litispendencia, de la exacta información a la contraparte -imprescindible para que ésta pueda preparar su defensa-, de la delimitación de los poderes del juez y de la cosa juzgada. Cuando, excepcionalmente, se dispone la oralidad para este acto -con el fin de facilitar la superación de obstáculos culturales- no existe ahorro de tiempo, sino dedicación del tiempo en ámbitos diferentes -en la oficina judicial, en vez de en el despacho de un defensor profesional-. Un tiempo para el traslado al demandado es siempre necesario, sea la forma inicialmente escrita $u$ oral. El tiempo, en fin, para que el demandado pueda reaccionar, tampoco debe ser esencialmente diverso si se trata de un plazo -máximo, perentorio- para una contestación escrita, o de un plazo -mínimo, dilatorio- para preparar la defensa para desarrollar en una vista oral. En ambos supuestos está en juego el derecho de defensa.

$2^{\circ}$ ) La escritura es, también, la forma más idónea para el acto de contestación, principalmente por el factor "duración del proceso". Una contestación escrita contribuye a fijar con precisión los términos del debate, y, entre ellos, los hechos

${ }^{68}$ Peyrano, "La prueba", cit. nota n. 33, pp. 157-158.

${ }^{69}$ TARUfFo, "Orality and writting", cit. nota n. 33, pp. 198-199; informe nacional de (Italia) BIAVATI, "Oral and written", cit. nota n. 49, p. 322. 
controvertidos; de ese modo se define el objeto de la prueba, lo que permite a las partes preparar una proposición de prueba ajustada a la necesidad de la misma. Ni excesiva, con sobrecarga inútil de la actividad preparatoria de las partes. Tampoco insuficiente, lo que podría justificar suspensiones o audiencias adicionales para complementar una prueba cuya deficiencia no sería atribuible a la negligencia de las partes.

$\left.3^{\circ}\right)$ Respecto de la etapa procesal situada entre demanda-contestación y audiencia principal se suscitan ciertas perplejidades en cuanto a la forma más eficiente.

Con relación a la "audiencia previa" de la LEC española de 2000, ha indicado recientemente Taruffo que la oralidad a la que se sujeta es un factor de eficiencia, puesto que, si todo lo que debe hacerse durante la misma, ${ }^{70}$ tuviera que articularse mediante intercambio de escritos, sería necesario mucho tiempo. ${ }^{71}$ No obstante, cuando el mismo autor enfatiza la eficiencia de la escritura para la preparación de los litigios más complejos, ${ }^{72}$ acaba por poner en cuestión la eficiencia de la oralidad en esta etapa, al menos desde la perspectiva del objetivo de conseguir una sentencia acertada.

En mi opinión, después de una demanda y de una contestación escritas, después de un plazo suficiente para esta contestación y para la preparación de la audiencia previa por las partes, la forma oral no sólo es eficiente en atención al factor "duración del proceso", sino que tampoco menoscaba las posibilidades de contradicción de las partes, dado que éstas ya son conocedoras del contexto temático del litigio y se hallan preparadas para reaccionar ante modificaciones no sustanciales. Por otra parte, como la preparación de la prueba que se propone y admite en la audiencia preliminar se hace después de esta audiencia y antes de la principal, tampoco experimenta perjuicio el derecho a contradecir mediante la prueba, porque la audiencia principal puede ser señalada atendiendo al tiempo necesario para preparar la práctica de todos los medios de prueba admitidos.

$4^{\circ}$ ) Por fin, en cuanto a los actos de práctica de la prueba, siempre que se trate de medios de prueba consistentes en declaraciones personales, o susceptibles, por su naturaleza, de que su contenido sea públicamente percibido, considero más eficiente la oralidad -con la inmediación y la concentraciónen atención, principalmente, al respeto a las garantías fundamentales y a la calidad de la sentencia. Es cierto que sobre el factor "duración del proceso"

\footnotetext{
${ }^{70}$ Recuérdese: si las partes no concluyen el proceso por acuerdo, han de debatirse y resolverse, en su caso, cuestiones procesales previas, deben ser fijados con precisión los hechos controvertidos, proponerse la prueba por la partes y resolverse sobre su admisión por el juez.

${ }^{71}$ TARUFFO, "Orality and writting", cit. nota n. 33, p. 191.

${ }^{72}$ TARUfFo, "Orality and writting", cit. nota n. 33, pp. 193-194.
} 
puede tener una incidencia negativa, especialmente si el servicio público de la justicia no está bien organizado y no tiene una dimensión proporcionada a la demanda. Otros inconvenientes sobre la duración que se achacan a la oralidad en este conjunto de actos procesales pueden evitarse bien sea mediante unos deberes profesionales del juez de poco discutible fundamento, ${ }^{73}$ bien mediante justificadas excepciones destinadas a salvar la vigencia general de la oralidadinmediación-concentración. ${ }^{74}$

Tal vez sea cierto que un procedimiento predominantemente oral, gestionado por un número de órganos jurisdiccionales razonable -atendidas las abundantes y variadas necesidades que requieren atención presupuestaria en un Estado de nuestro tiempo- pueda implicar una mayor duración de los procesos sometidos a esa forma procedimental. Aunque así fuera, no estaría justificado concluir que el sistema procesal civil es ineficiente en atención al factor "duración del proceso".

Poco antes recordábamos que la combinación de las formas procedimentales puede consistir en que, en un ordenamiento que opte por el predominio de la oralidad para los procedimientos comunes, se establezcan también procedimientos que, principalmente por la actitud de la parte demandada, puedan alcanzar sus resultado mediante pocos trámites y, además, justificadamente escritos. Pienso, por ejemplo, en el procedimiento monitorio en Derecho español, que, según datos del año 2008, fue el procedimiento seguido en casi un $38 \%$ de la litigiosidad civil, y, además, condujo a resultados de pago en el $10^{\prime} 9 \%$ de los casos, y de creación de título ejecutivo con inicio de la ejecución en un $36^{\prime} 9 \% .^{75}$

Con esta combinación de procedimientos el sistema merece ser considerado, en su conjunto, eficiente, porque los tribunales resultan justificadamente descargados de la tramitación común de un número importante de procesos declarativos, y, de ese modo, pueden incrementar el tiempo de dedicación a los asuntos que la requieren en mayor medida.

Un sistema procesal civil ordenado de ese modo enervaría uno de los argumentos relevantes para atribuir responsabilidad al Estado por dilaciones indebidas en la administración de justicia. ${ }^{76}$ Sin descartar la posibilidad de atribución

\footnotetext{
${ }^{73}$ Por ejemplo: el deber, antes de que se haga efectivo un eventual cambio de destino de un juez profesional, de dictar sentencia sobre los asuntos cuya audiencia principal ha sido presidida por él.

${ }^{74}$ En el siguiente apartado VI pueden verse las soluciones que incorpora, para excepciones justificadas, la LEC española de 2000.

${ }^{75}$ Consejo General del Poder Judicial España, "Estadísticas", La justicia dato a dato Año 2008, pp. 31 y 57, En: http://www.poderjudicial.es/eversuite/GetDoc?DBName $=$ dPortal\&UniqueKeyValue $=79636$ \&Download=false\&ShowPath=false [visitado el 15/03/2010].

${ }^{76}$ Sobre los criterios en general para esta atribución, en la jurisprudencia del TEDH, DíEZ-PICAZO JIMÉNEZ, I., Poder Judicial y responsabilidad, Editorial La Ley, Madrid, 1990, pp. 108-115.
} 
de responsabilidad por el concreto devenir de asuntos singulares, es importante, para reducir los casos de responsabilidad, que los Estados organicen su sistema judicial de forma que pueda cumplir con la exigencia de evitar la dilaciones indebidas, ${ }^{77}$ lo que requiere una adecuada organización y dotación del servicio público de justicia y una adecuada ordenación de los procedimientos judiciales, en la que se combinen las diferentes formas de manera que pueda alcanzarse la mayor eficiencia.

\section{Incidencia de las formas procedimentales sobre el factor "coste del} proceso". La Justicia como servicio público: optimización organizativa y gasto público destinado a su sostenimiento

La incidencia de las formas del procedimiento sobre el coste económico de éste es de difícil determinación. De entrada, lo que razonablemente puede considerarse "coste del proceso" presenta una compleja variedad de componentes: el gasto público destinado a financiar los recursos personales y materiales para el funcionamiento de la Administración de justicia, los gastos privados para acceder a la Justicia -que, en parte, acaban siendo gasto público, en cuanto debe garantizarse la defensa profesional de quienes carecen de recursos económicos-, y los costes económicos externos atribuibles a las disfunciones del sistema judicial y sus repercusiones sobre la economía. En segundo lugar, considerando los costes cuya concreción cuantitativa es más accesible (los dos primeros entre los mencionados antes), no siempre pueden conseguirse datos suficientes, ni estudios previos sobre los mismos (realizados -obviamente-con técnicas no jurídicas, sino sociológicas o económicas) que permitan alcanzar conclusiones suficientemente consistentes sobre la relación formas procedimentales -costes (determinados) del proceso. ${ }^{78}$

\footnotetext{
${ }_{77}$ Interesante, en este aspecto, TEDH, Caso Di Mauro contra Italia, sentencia de 28 de julio de 1999, en cuyo Fundamento jurídico 23 podemos leer: "El Tribunal señala de entrada que el artículo 6.1 del Convenio obliga a los Estados contratantes a organizar su sistema judicial de tal forma que puedan cumplir con las exigencias de esta disposición (Sentencia Salesi contra Italia de 26 febrero 1993, serie A núm. 257-E, p. 60, ap. 24). Reafirma la importancia que se concede a que la justicia no se administre con retrasos que comprometan su eficacia y su credibilidad (Sentencia Kattle Klitsche de la Grange contra Italia de 27 octubre 1994, serie A, núm. 293-B, p. 39, ap. 61). (...) El Tribunal señala a continuación, haber dictado desde el 25 de junio de 1987, fecha de la Sentencia Capuano contra Italia (Serie A, núm. 119), 65 sentencias constatando la violación del artículo 6.1 en los procedimientos que se hubieran prolongado más allá del «plazo razonable» ante los Tribunales civiles de las distintas regiones italianas (cursiva mía). (...) La repetición de las violaciones constatadas muestra que hay una acumulación de incumplimientos de idéntica naturaleza y lo suficientemente numerosos para que no se reduzcan a incidentes aislados. Dichos incumplimientos reflejan una situación, que perdura, a la que todavía no se ha puesto remedio y para la que los justiciables no disponen de ninguna vía de recurso interna. (...) Esta acumulación de incumplimientos es, por lo tanto, constitutiva de práctica incompatible con el Convenio".

${ }^{78}$ Tengo presente, para estas cuestiones, el reciente estudio de PAstor Prieto, S., "¿Penuria de medios? Un análisis empírico de los costes públicos y privados visibles y ocultos de la Justicia", de próxima publicación en la obra colectiva La justicia procesal, correspondiente al ciclo de conferencias, dirigido por el Prof. Dr. Faustino Gutiérrez-Alviz y Conradi, organizado por el CGPJ, y celebrado en Madrid, los días 17 al 19 de septiembre de 2008. Cito por las pruebas de imprenta, pp. 167-254.
} 
Incluso limitando nuestra consideración a la incidencia sobre el gasto público destinado a sostener el servicio público de la Justicia, la tarea no resulta sencilla.

Por un lado, la creación y el mantenimiento de este servicio público repercute sobre el gasto público de un modo en el que no prepondera la forma del procedimiento, porque el estricto establecimiento de una organización judicial dotada de los recursos humanos, medios materiales y técnicas organizativas idóneas, justifica por sí solo la mayor parte del gasto, sin que resulten significativas diferencias determinadas por las formas procedimentales.

En segundo término, también con cierta independencia de esas formas, existe un margen para optimizar el aprovechamiento de los recursos disponibles a partir de un gasto público dado. Se puede mejorar la organización del trabajo de los tribunales de modo que se obtenga el mayor rendimiento de los medios materiales (edificios, equipamientos; en especial, las posibilidades ligadas al uso de equipamientos informáticos) y de los recursos humanos auxiliares (por ejemplo: creación de servicios comunes a varios órganos jurisdiccionales, que posibiliten rentabilizar al máximo las tareas de apoyo). ${ }^{79}$

En fin, también es (sustancialmente) independiente de la forma del procedimiento, la necesidad de asignar gasto público a la asistencia técnico-jurídica de las personas sin recursos económicos, lo que resulta imprescindible para una aproximación a la igualdad real entre las partes procesales en un proceso en el que la defensa técnica sea preceptiva o esté permitida ( $y$, por tanto, pueda ser utilizada libremente por la parte con capacidad económica para contratarla). ${ }^{80}$

En el estudio más arriba citado de Ramos Romeu se hace una apreciación de la incidencia de la forma procedimental predominante sobre los costes del proceso, considerando sólo procesos de reclamación de cantidad y de desahucio, aunque a partir de estadísticas de ámbito mundial. ${ }^{81}$ Concluye que "el uso de la escritura va asociado a un proceso más caro. Vemos que el uso de la escritura no aumenta los costes totales del proceso, y quizá reduce los costes para la parte, pero sí se aprecia que un mayor uso de la escritura aumenta los costes del tribunal e igualmente entraña que los ciudadanos manifiesten que la justicia es menos asequible" ${ }^{82}$

En mi opinión, si se atiende a la diversidad de los litigios civiles -no sólo a algunas de sus clases- y a la repercusión que la oralidad puede tener sobre una

\footnotetext{
${ }^{79}$ Con referencia a España, véanse, entre otros, PASTOR, "¿Penuria de medios?", cit. nota n. 78, pp. 244-245 de las pruebas de imprenta; Perdiguero Bautista, E., "La oficina judicial", en Gutiérrez-Alviz y Conradi, Dir., Justicia: Poder y servicio público, CGPJ, Madrid, 2007, pp. 267-292; Moreno Catena, V., "La Justicia en acción", en Justicia, cit. nota n. 78, pp. 295-326.

${ }^{80}$ Sobre esta parte del gasto público en España, PASTOR, "¿Penuria de medios?", cit. nota n. 78, pp. 195-197 de las pruebas de imprenta.

${ }^{81}$ Ramos, “Forma del proceso", cit. nota n. 60, pp. 482-483.

${ }^{82}$ Ramos, "Forma del proceso", cit. nota n. 60, p. 485.
} 
mayor duración del proceso, a causa de su incidencia en la organización del tiempo de trabajo de los jueces, ${ }^{83}$ la conclusión más probable es la de que el funcionamiento de un procedimiento (predominantemente) oral sin dilaciones indebidas requiere un mayor gasto público en la creación de órganos jurisdiccionales, particularmente un mayor número de jueces. ${ }^{84}$

Realmente, en un procedimiento escrito sin corruptelas en cuanto al cumplimiento del deber de presencia judicial en determinados actos, realmente ocurriría lo mismo que en un procedimiento oral. Si no ha sido así, o si no lo es en los ordenamientos en que el procedimiento escrito subsiste, se debe a que determinadas funciones (particularmente las de recepción de pruebas personales) no son cumplidas por el juez, sino - de acuerdo con la ley, o contra ella- por auxiliares del tribunal. ${ }^{85}$

Por otro lado, cabría pensar que la oralidad conduce a aumentar los gastos privados, principalmente los consistentes en los honorarios de los abogados, porque su tiempo no sólo debe destinarse a preparar su actuación en las audiencias, sino que debe estar disponible durante la celebración de éstas, incluso con los inconvenientes ligados a los retrasos respecto de las horas de señalamiento y a eventuales suspensiones. No obstante, es difícil detectar esta incidencia, porque los datos disponibles sobre la cuantificación de los honorarios inclinan a pensar que se halla principalmente en función de la cuantía del pelito y no de la forma de su tramitación. ${ }^{86}$

VI. EL PREDOMINIO DE LA ORALIDAD EN LOS PROCEDIMIENTOS PARA LA TUTELA JURISDICCIONAL DECLARATIVA DE LA LEC ESPAÑOLA DE 2000: LOS FACTORES Y LOS RESULTADOS DE UN CAMBIO HISTÓRICO

La LEC española de 2000 no sólo debía dar cumplimiento a un imperativo constitucional (art. $120 \mathrm{CE}$ ), sino quebrar una recalcitrante tendencia histórica

\footnotetext{
${ }^{83}$ Véase el anterior apartado $\mathrm{V}, 2$.

${ }^{84}$ Así pienso que debe interpretarse el comentario de Pastor, “¿Penuria de medios?”, cit. nota n. 78, p. 241: "La demanda de más tutela judicial y una mejor calidad de ésta ha aumentado notablemente en los últimos años en buena parte como consecuencia de cambios de las leyes procesales y sustantivas de enorme calado presupuestario, aunque con frecuencia se afirmase por el legislador que apenas tenían impacto alguno de ese tipo. Nos referimos a cambios como (...) la Ley de Enjuiciamiento civil (cursiva mía)".

${ }^{85}$ Concuerdo con Ramos,"Forma del proceso", cit. nota n. 60, p. 477, nota 5, en su "ingenua" advertencia de falta de explicación a la necesidad de mayor número de jueces en caso de procedimiento oral: "El proceso escrito necesita también de jueces para leer los escritos". Lo que tanto Ramos Romeu, como yo, sabemos que ocurre es que, en un procedimiento escrito, una parte del trabajo del juez se desplaza hacia los auxiliares, porque "de hecho" -no digo "de Derecho"- se puede. Tal vez esta solución origine menos gasto público, pero también reduce la calidad de la Justicia.

${ }^{86}$ PASTOR, “¿Penuria de medios?", cit. nota n. 78, pp. 210-217, 245-246.
} 
del proceso civil español, que mantenía, normativa y -sobre todo- prácticamente el predominio de la forma escrita, situándose al margen de la que fue una tendencia europea en el siglo XIX. ${ }^{87}$ Para alcanzar estos objetivos de una manera efectiva, era necesario coordinar una ordenación jurídica adecuada con la creación de las condiciones materiales que hicieran posible (ineludible, exigible) el cumplimiento de esa ordenación.

Si se atiende a la duración del proceso, el resultado ha sido positivo. Pero esta valoración es esencialmente dinámica, porque el incremento de la litigiosidad, a causa -por ejemplo- de situaciones de crisis económica, puede invertir el sentido de la valoración si la oferta del servicio público de justicia no se acompasa a una demanda creciente.

1. La ordenación jurídica: ¿Cómo predomina la oralidad en la mayor parte de los procedimientos? El ámbito del predominio de la escritura

Distinguiremos las dos modalidades de combinación de oralidad y escritura a las que hicimos referencia en el apartado IV de este trabajo.

\section{a) Los procedimientos con predominio de la oralidad y el modo de ese predominio}

La oralidad es la forma predominante en los procedimientos comunes -el ordinario y el Ilamado verbal- y en los procedimientos comunes con especialidades. En los procedimientos propiamente especiales -que la LEC de 2000 ha reducido drásticamente- los hay con predominio de la oralidad (procesos de estado civil) y con posible predominio de la escritura (pienso, principalmente, en los procedimientos de estructura monitoria, a los que me referiré, brevemente, en el siguiente sub-apartado B). ${ }^{88}$

Veamos, a continuación, resumidamente, cómo ha combinado la LEC oralidad y escritura, dando predominio a la primera. ${ }^{89}$

\footnotetext{
${ }^{87}$ Muy sintéticamente, puede ser ilustrativo del aislamiento del proceso civil español de las tendencias europeas que propiciaron la introducción de la oralidad, Ortells, M., "Le Code de Procédure Civile de 1806 et la première codification procédurale espagnole: parallélismes, coïncidences, divergence », en 1806-1976-2006. De la commémoration d'un Code à l'autre: 200 ans de procédure civile en France, Editorial LexisNexis Litec, Paris, 2006, pp. 167-186.

${ }^{88}$ Sobre los tipos de procedimientos en la LEC española de 2000 debo remitir a Ortells y otros, Derecho, cit. nota n. 22, pp. 593-607.

${ }^{89}$ La información puede ampliarse en Ortells, M., "Der neue spanische Zivilprozess. Leitlinien der Ley de Enjuiciamiento Civil vom. 7 Januar 2000", en Zeitschrift für Zivilprozess International núm. 5, 2000, pp. 102-103; Ortells y otros, Derecho, cit. nota n. 22, pp. 361-366; informes nacionales de Armengot y de Picó, ambos en CARPI; OrTells, Oralidad y escritura, v. I, cit. nota n. 30, pp. 225-240, pp. 361-370, respectivamente; Richard GonZÁlez, M., "Limitaciones a la oralidad en la práctica de la prueba pericial en el proceso civil español, en Carpi; Ortells, Oralidad y escritura, v. II, cit. nota n. 30,
} 
La escritura rige los actos de alegación y petición iniciales del proceso, aunque con excepciones en la modalidad procedimental de "juicio verbal". La oralidad, en cambio, es la forma para que las partes realicen las modificaciones legalmente permitidas de aquellos actos iniciales, para la proposición de la prueba y, sobre todo, para la práctica de la misma, así como para las alegaciones conclusivas -mediante las cuales las partes analizan el material ya introducido en el proceso-.

La demanda y la contestación son escritas, también la reconvención y su contestación por el actor. Como excepción, en el "juicio verbal" sólo la demanda es escrita y el demandado tiene la carga de comunicar por escrito antes de la vista su propósito de reconvenir y el objeto de la reconvención.

Las modificaciones legalmente permitidas de la demanda y la contestación se realizan oralmente, incluso en la modalidad procedimental de "juicio ordinario". Se formulan en la audiencia previa al juicio o en el acto del juicio, salvo que las circunstancias que justifican la modificación de la demanda o de la contestación hubieran ocurrido después de iniciada la práctica de la prueba en el acto del juicio, en cuyo caso la modificación se realizará por escrito con la proposición de prueba correspondiente.

La LEC persigue establecer la oralidad (y las reglas relacionadas de concentración e inmediación) en la práctica de la prueba, principalmente en cuanto a los medios de prueba de declaración de las partes, testifical y pericial -exposición del dictamen y examen contradictorio por las partes-.

Por regla general ${ }^{90}$ los medios de prueba deben ser practicados en unidad de acto (art. 290 LEC). Eso significa: dentro de una actuación procesal compleja en la que están simultáneamente presentes el tribunal y las partes, y que se desarrolla, por regla general, sin interrupción temporal hasta la terminación de las actividades de práctica. En el juicio ordinario esa actuación es el juicio (art. 431 LEC). En el juicio verbal es la vista (art. 443.4 LEC).

Ciertamente los juicios y vistas pueden interrumpirse por las causas legales, pero si al reanudarse han transcurrido más de veinte días desde la interrupción

pp. 245-254; VÁZQUEZ, "La oralidad y la escritura", cit. nota n. 10, pp. 257-276; GutiéRrez BARRENECHEA, A., "La oralidad y sus implicaciones en el proceso civil", pp. 383-394; SÁnCHEZ, R. Juan, "El juicio verbal español: principales problemas para su desarrollo concentrado", pp. 415-424. Las dos últimas obras ver en CARPI, ORTells, Oralidad y escritura, v. II, cit. nota n. 30.

90 Hay excepciones: $1^{\text {a)}}$ La prueba anticipada en sentido estricto, justificada en que la espera de la práctica conduciría a perder el resultado probatorio o a encarecer o dilatar su adquisición de modo importante (art. 293 LEC); 2a ) La prueba que debe ser practicada fuera de la sede del tribunal, que debe ser practicada antes del juicio para que su resultado pueda ser debatido en éste; $3^{a}$ ) En mi opinión, los medios de prueba que, si debieran practicarse en el juicio, podrían dar lugar -por razones diferentes a los dos supuestos anteriores- a la suspensión o interrupción de éste; 4a) En fin, pueden practicarse después del juicio medios de prueba que no pudieron serlo a su tiempo, pero respecto de los cuales la ley establece una justificada excepciona a la preclusión (art. 435 LEC). 
se señalará nuevo juicio, en el que se reiterará la práctica de la prueba (art. 193 LEC).

Sólo los jueces y magistrados que, integrando el órgano jurisdiccional, han presenciado y dirigido la práctica de los medios de prueba en los actos del juicio o de la vista, pueden dictar sentencia en el proceso correspondiente. La LEC garantiza la inmediación con disposiciones preventivas, como la que dispone la celebración de nuevo juicio o vista si éstos se hubieran interrumpido y, en el momento de la reanudación, el juez hubiera sido sustituido (art. 193.3 LEC), y con disposiciones "represivas", como la que sanciona con la nulidad de pleno derecho de las actuaciones practicadas infringiendo el deber de inmediación (art. 137.3 LEC).

La forma oral en los medios de prueba personales (declaración de las partes, testifical) y en la prueba pericial -exposición del informe por los peritos y examen contradictorio por las partes- ha sido reforzada porque el texto definitivo de la LEC -a diferencia de las previsiones del proyecto de ley- no autoriza escritos preparatorios para los interrogatorios. Los interrogatorios se producen verbalmente en los actos del juicio o de la vista.

\section{b) Procedimientos con eventual predominio de la escritura}

Hay algunos procedimientos en los que la escritura puede predominar, hasta convertirse casi en la única forma utilizada, e insisto en el "puede", porque el predominio es eventual y depende, principalmente, ${ }^{91}$ de cuál sea la actitud del demandado frente a la demanda.

Una actitud defensiva del mismo determina una continuación del procedimiento con los elementos de oralidad generales, pero su allanamiento o la simple inactividad conducen a la finalización del proceso sin más trámites que los escritos. Es el caso del proceso monitorio común (arts. 814-817 LEC) y de los monitorios especiales cambiario (arts. 821,822 y 825 LEC) y en materia de propiedad horizontal (art. 7 Ley de Propiedad Horizontal). También puede ocurrir esto en algunos procedimientos comunes con especialidades debidas a la materia litigiosa, como, por ejemplo, aquellos en que se hacen valer pretensiones de defensa de derechos reales inscritos en el Registro de la Propiedad (arts. $250.1 .7^{\circ}$ y $440.2 \mathrm{LEC}$ ), o determinadas pretensiones relativas a contratos

\footnotetext{
${ }^{91}$ También hay razones distintas a la que destaco en el texto: la clase de prueba disponible para el pleito (documental e informes periciales, acompañados a demanda y contestación y no impugnados) y actitud de ambas partes, que puede conducir a que el proceso termine con sentencia dictada después de la audiencia previa (art. 429.8 LEC); clase de cuestión litigiosa (división de patrimonios, para la que es decisiva la determinación y valoración de activos y pasivos y la partición, cuestiones cuya solución suele depender de documentos y de una pericial específica) y actitud de las partes, que puede conducir a la finalización del proceso sin la audiencia con pruebas que sería necesaria si hubiera oposición a la partición por alguna de las partes (art. 787 LEC).
} 
sobre venta a plazos de bienes muebles o a contratos de leasing (arts. 250.1.10 y $11^{\circ}$ y 440.4 LEC).

\section{El aumento de gasto público destinado al servicio de Justicia}

Para ilustrar de manera plenamente convincente hasta qué punto un sistema procesal civil con predominio de la oralidad-como el que acabamos de describir brevemente- puede funcionar efectiva y realmente debido a un correlativo incremento del gasto público destinado al servicio de justicia, sería necesario partir de estudios elaborados con técnicas de sociología de la organización y económicas, que reflejaran los gastos de personal -jurisdiccional y auxiliar-, los gastos corrientes -en instrumentos auxiliares; por ejemplo, para las grabaciones audiovisuales- y las inversiones en equipamiento informático y en adecuación y renovación de edificios judiciales, ligados a la implementación de aquel sistema. Obviamente, esos estudios ofrecerían datos sobre el gasto público en Justicia desagregados en cuanto al ámbito civil de la misma.

No dispongo de estudios previos que reúnan esas características, de modo que tendré que limitarme a apreciaciones sobre la evolución del gasto público en Justicia, en España y durante la implantación del nuevo sistema procesal civil, que aunque son muy generales, no dejan de ser significativas.

Resumidamente la situación puede ser descrita con el siguiente comentario de Pastor Prieto: "En términos nominales, el gasto se duplicó entre 2000 y 2007, un crecimiento superior al de todo el decenio 1990-2000. En términos reales, el aumento del gasto fue de casi un $70 \%$ entre 2000 y 2007, frente a algo menos del 40\% en el decenio 1990-2000". ${ }^{92}$ Téngase en cuenta que el año 2000 fue el año de vacatio legis de la Ley $1 / 2000$, que contenía el texto de la nueva LEC.

Es razonable pensar que buena parte de este incremento contribuyó a la implantación efectiva del nuevo sistema procesal civil.

\section{Los resultados obtenidos: la mejora en la duración de los procesos civiles. Los riesgos de inversión de la tendencia}

La cuestión es, ahora, comprobar si ese cambio de modelo procedimental, acompañado de un razonable incremento del gasto público que hace posible su real aplicación, ha hecho más eficiente el proceso civil español. Ya apunté más arriba que era inseguro apreciar la mayor eficiencia atendiendo a la mejora en la calidad de las sentencias, porque la misma es difícilmente evaluable. ${ }^{93}$

\footnotetext{
92 PASTOR, “¿Penuria de medios?", cit. nota n. 78, p. 173.

${ }^{93} \mathrm{Si}$ atendemos a los porcentajes de confirmación de sentencias recurridas en apelación, podríamos decir que la calidad es buena porque, respecto de sentencias de juzgados de primera instancia no especializados, el porcentaje está situado, desde 2003 a 2008, en el entorno del $63 \%$, y, en los años de existencia de los Juzgados de lo Mercantil, el porcentaje no ha bajado del 70’4 \%. La información
} 
Una referencia más segura de la eficiencia -partiendo de la base de que un procedimiento escrito presenta idéntica dificultad para evaluar la calidad de las sentencias- puede considerarse la reducción de los tiempos de duración del proceso.

El Consejo General del Poder Judicial ofrece datos sobre estimaciones de las duraciones medias de los asuntos terminados en cada período. Las estimaciones se obtienen por medio de un modelo matemático que hace uso de los números de asuntos ingresados, resueltos y en trámite al comienzo de cada período, datos facilitados por la Estadística Judicial del Consejo General del Poder Judicial. La tabla que incluimos a continuación se ha elaborado partiendo de esos datos. ${ }^{94}$ Los datos se refieren a la duración en meses de la primera instancia, ante las diversas clases de órganos jurisdiccionales que conocen de esta etapa procesal. Incluyen dos años en los que la LEC de 2000 no estaba en vigor o no fue aplicable (1999 y 2000).

\begin{tabular}{|l|l|l|l|l|l|l|l|l|l|l|}
\hline & $\mathbf{1 9 9 9}$ & $\mathbf{2 0 0 0}$ & $\mathbf{2 0 0 1}$ & $\mathbf{2 0 0 2}$ & $\mathbf{2 0 0 3}$ & $\mathbf{2 0 0 4}$ & $\mathbf{2 0 0 5}$ & $\mathbf{2 0 0 6}$ & $\mathbf{2 0 0 7}$ & $\mathbf{2 0 0 8}$ \\
\hline $\begin{array}{l}\text { Juzgados de } \\
\text { Primera } \\
\text { Instancia }\end{array}$ & 10,20 & 9,68 & 9,62 & 8,80 & 7,94 & 7,9 & 7,7 & 7,9 & 7,2 & 6,9 \\
\hline $\begin{array}{l}\text { Juzgados de } \\
\text { Primera } \\
\text { Instancia } \\
\text { (e Instrucción) }\end{array}$ & 9,71 & 9,23 & 9,51 & 8,48 & 7,81 & 7,7 & 7,7 & 7,9 & 8,1 & 8,1 \\
\hline $\begin{array}{l}\text { Juzgados de } \\
\text { Familia }\end{array}$ & 6,20 & 6,11 & 6,04 & 5,42 & 5,01 & 3,9 & 3,9 & 4,3 & 4,1 & 4,0 \\
\hline $\begin{array}{l}\text { Juzgados de } \\
\text { lo Mercantil }\end{array}$ & ---- & ---- & ---- & ---- & --- & 5,5 & 10,6 & 15,6 & 21,6 & 22,9 \\
\hline
\end{tabular}

Salvo para los Juzgados de lo Mercantil -órganos jurisdiccionales especializados, con competencia objetiva en determinadas materias mercantiles, y que iniciaron su funcionamiento en 2004- los datos sobre duración de la primera instancia han experimentado una constante mejora -en el sentido de reducción de la duración- desde que se inició la aplicación de la nueva LEC y hasta 2008. La mejora es menos pronunciada, aunque no deja de ser perceptible, en los

puede encontrarse en los documentos titulados La Justicia dato a dato, correspondiente a los años 2003 hasta el 2008, que pueden encontrarse en la sección de estadísticas del Consejo General del Poder Judicial. En: http://www.poderjudicial.es [visitado el 15/03/2010]. Para la crítica de este indicador de calidad, es interesante consultar DoméNECH PAsCuAL, G., Juzgar a destajo. La perniciosa influencia de las retribuciones variables de los jueces sobre el sentido de sus decisiones, Civitas - Thomson Reuters, Madrid, 2009, p. 53 y, más en general, pp. 55-93.

${ }^{94}$ Nuevamente hay que remitir a los documentos titulados La Justicia dato a dato, correspondiente a los años 2003 hasta el 2008, que pueden encontrarse en la sección de estadísticas del Consejo General del Poder Judicial. En: http://www.poderjudicial.es [visitado el 15/03/2010]. De esos documentos se ha extraído también la explicación del cálculo de las estimaciones de duración que figura en el texto. 
procesos que dirigen los Juzgados de Primera Instancia e Instrucción, lo que, probablemente, se debe a la incidencia de la competencia penal, que estos Juzgados comparten con la civil, sobre la carga de trabajo de los mismos.

La evolución de las medias estimadas de duración de los procesos ante los Juzgados de lo Mercantil es, obviamente, negativa. Probablemente se debe a que una parte importante de la competencia objetiva de estos Juzgados lo son los procesos concursales, cuya complejidad -parcialmente derivada de la combinación de actividades declarativas y ejecutivas- conduce a unas medias de duración difícilmente comparables con las de proceso de declaración que tiene por objeto una pretensión o, en ocasiones, algunas acumuladas.

Pero el espectacular aumento de esas medias de duración, especialmente en los años 2007 y 2008, revelan también la incidencia de otro factor: el incremento de los procesos concursales debido a la coyuntura de crisis económica, que se atraviesa desde hace meses, y que está desbordando la oferta del servicio público de justicia que se presta por esta clase de órganos jurisdiccionales.

Y existe el riesgo claro de que esa incidencia de la crisis, en términos de fuerte incremento de la litigiosidad, se extienda a las otras clases de órganos jurisdiccionales con competencia en materia civil, aumentando su carga de trabajo y, con ella, las medias de duración de los procesos. ${ }^{95}$

En definitiva, se demuestra que el eficiente funcionamiento de un sistema procesal civil ha de respetar las garantías procesales fundamentales y a contar con una buena opción en cuanto a las formas del procedimiento, pero requiere imprescindiblemente de un adecuado nivel de gasto público en el servicio de justicia, que dé respuesta a la demanda social del mismo.

\footnotetext{
${ }^{95}$ Remito a la publicación del Consejo General del Poder Judicial, Datos de Justicia. Boletín Estadística, núm. 17, julio 2009. En: http://www.poderjudicial.es [visitado el 15/03/2010] p. 2, donde se muestran las cifras de asuntos ingresados como procedimientos ordinarios, verbales, monitorios cambiarios y ordinarios en el período previo al inicio de la crisis económica y en lo que llevamos de ésta, y se comparan con el mismo dato del trimestre del año anterior. Los asuntos ingresados en el primer trimestre de 2009 supusieron un incremento, respecto de los que lo hicieron en el mismo trimestre del año 2008, del $24^{\prime} 3 \%$-para los procedimientos ordinarios-, del 16'1\% -para los verbales-, del $121^{\prime} 7 \%$-para los cambiarios-y del 70'6 \% -para los monitorios ordinarios-. Si se comparan con los porcentajes de incremento entre los trimestres de 2007, la diferencia es espectacular.
} 
